\title{
ОБЗОРЫ И ЛЕКЦИИ
}

УДК 504.7:631.412

\section{ИНВЕНТАРИЗАЦИИ ПОГЛОЩЕНИЯ МЕТАНА ПОЧВАМИ}

\author{
Глаголев М.В. ${ }^{1,2,3)}$, Филиппов И.В. ${ }^{2)}$
}

\author{
${ }^{1)}$ Московский государственный университет им. М.В. Ломоносова, \\ ${ }^{2)}$ Югорский государственный университет (2. Ханты-Мансийск) \\ ${ }^{3)}$ Институт лесоведения РАН (пос. Успенское, Московская обл.)
}

$$
\text { m_glagolev@mail.ru }
$$

В работе кратко описаны основные группь методов получения оценок региональных потоков газов на границе почва/атмосфера (на примере поглощения метана почвами): простейшая инвентаризация, прямое математическое моделирование и решение обратной задачи. Подробно рассмотрены различные реализации метода простейшей инвентаризации: оценка окисления в почвах разных биомов и/или разной структуры. Показано, что широко известный метод оценки окисления на основе знаний о структуре почвы статистически недостоверен (по крайней мере на уровне значимости 0.05, обычно используемом в биологических и почвенных исследованиях). В заключительном разделе работы методы простейшей инвентаризации обсуждаются в приложении к оченке поглощения $\mathrm{CH}_{4}$ почвами России. $K$ сожалению, эти оченки имеют весьма большие погрешности, а это явно свидетельствует о плохой изученности проблемы поглощения почвенного метана. Тем не менее, представляется, что в качестве значения годичного поглощения $\mathrm{CH}_{4}$ почвами РФ, наиболее близкого к оченкам различных авторов, можно принять $3.6 \mathrm{Mm} /$ год.

Ключевые слова: метан, почвы России, поглощение метана почвами.

Цитирование: Глаголев М.В., Филиппов И.В. 2011. Инвентаризации поглощения метана почвами // Динамика окружающей среды и глобальные изменения климата. Т. 2. № 2(4). EDCCrev0002.

\section{ВВЕДЕНИЕ}

Большое значение метана для климата Земли обусловлено тем, что, во-первых, это важный «парниковый» газ и, во-вторых, он оказывает сильное влияние на химию атмосферы (т.к. является стоком для гидроксил-радикалов в тропосфере) [Whiticar, 1999]. Увеличение концентрации парниковых газов в атмосфере считается одной из причин глобального изменения климата.

В эмиссии метана участвуют как антропогенные, так и естественные источники, главными из которых служат болота. Согласно конвенции по климату, принятой в 1992 г., каждая страна должна составить свой баланс парниковых газов, в первую очередь $\mathrm{CO}_{2}$ и $\mathrm{CH}_{4}$ [Заварзин, 1995]. Однако, невозможно провести измерения в каждой географической точке, поэтому особое значение приобретают теоретические или, хотя бы, эмпирические соотношения, позволяющие прогнозировать величины потоков на неисследованных территориях [Глаголев, 2006].

В конце 60-х гг. ХХ-го в. Робинсон и Робинс ${ }^{1}$, не установив каких-либо иных путей удаления метана из атмосферы, предположили, что он быстро окисляется на поверхности растительности. Однако особенности этого процесса не были выяснены ${ }^{2}$ [Хайди, 1976, с. 175], поэтому основным биологическим стоком метана из атмосферы считается его окисление в почве, размеры которого составляют, по разным оценкам, от 5 до 60 Тг·год ${ }^{-1}$ (в последние годы этот интервал неопределенности сократился до 2045 Тг.год $\left.{ }^{-1}\right)$, т.е. приблизительно от 1 до $10 \%$ глобальной эмиссии [King and Adamsen, 1992; Dörr et al., 1993; Dutaur and Verchot, 2007]. По абсолютному значению это примерно соответствовало скорости накопления метана в атмосфере в 90-х гг. XX в. [Ridgwell et al., 1999; Dutaur and Verchot, 2007].

\footnotetext{
${ }^{1}$ Robinson E., Robbins R., Sources, abundance, and fate of gaseous atmospheric pollutants, Stanford Research Institute Final Rept. Proj. PR-6755, Menlo Park, Calif., 1968; supplemental report, 1969. - цит. по [Хайди, 1976, с. 175, 219].

2 В принципе, речь может идти об окислении $\mathrm{CH}_{4}$ метанотрофными бактериями, если они поселятся на поверхности растительности. Но Хайди [1976, с. 175], конечно, имел в виду совершенно иное (как это видно из его следующего высказывания: «Неопределенности в известных механизмах удаления побудили... предположить, что... $\mathrm{CH}_{4}$ поглощается тканями растений в процессе фотосинтеза»). В свете представлений современной науки окисление метана самими растениями (особенно в процессе фотосинтеза) представляется крайне маловероятным.
} 
Кроме того, относительно небольшое потребление атмосферного метана может измениться при изменении типа землепользования и глобальном изменении климата [Potter et al., 1999].

Возможно, именно не слишком значительная доля почвенного окисления обусловила существенно меньшее внимание к его изучению по сравнению с источниками метана. Тем не менее, на локальном (вплоть до регионального) уровне значение почвенного стока метана может быть выше, чем в глобальном масштабе, в связи с чем этот сток может оказывать заметное влияние на динамику атмосферной концентрации метана в данном регионе, что необходимо учитывать при решении обратных задач идентификации источников метана на подстилающей поверхности по результатам измерения динамики его атмосферной концентрации. Действительно, пусть в некотором регионе рисовники, болота и полигоны захоронения твердых бытовых отходов (являющиеся основными источниками $\mathrm{CH}_{4}$ ) занимают очень малую площадь, а пашни и леса (являющиеся его стоками), напротив, занимают относительно большую площадь. Тогда ${ }^{3}$ в этом регионе сток будет составлять вовсе не $1-10 \%$ от источника, а может быть сравним или даже превалировать над ним.

Ранее мы предпринимали попытку обзора математического моделирования окисления $\mathrm{CH}_{4}$ в почве - [Глаголев, 2006], которая, по-видимому, осталась единственной в русскоязычной литературе. Однако эта работа охватывает, скорее, чисто теоретические и лабораторные модели, и не может использоваться для глобального моделирования почвенного стока метана (не говоря уже о том, что самая последняя из рассмотренных там моделей относится к концу прошлого века). Соответственно, в данном кратком обзоре мы ставим перед собой задачу познакомить читателя с простейшими схемами региональной (и глобальной) инвентаризации метанокисления, а в качестве примера использования этих схем оценим поглощение метана почвами России. Подчеркнем, что речь пойдет именно о получении региональных (и глобальных) оценок потока, а методы индивидуальных точечных измерений поверхностной плотности потока мы здесь не рассматриваем, как из-за ограниченности объема статьи, так и из-за того, что они были подробно описаны в литературе ранее - см., полевые методы, например, в [Dörr et al., 1993; Glagolev et al, 2000; Kammann et al., 2001; Morishita et al., 2004], а лабораторные методы - в [Born et al., 1990; King and Adamsen, 1992; Bender and Conrad, 1993; Cai and Yan, 1999]. Ниже везде, где мы упоминаем конкретные измерения, вошедшие в дальнейшие региональные или глобальные оценки, мы приводим ссылки на публикации, содержащие описания методов, использованных при проведении именно этих измерений.

\section{МЕТОДЫ ОЦЕНКИ РЕГИОНАЛЬНОГО ПОТОКА}

\section{Общий подход к оценке регионального потока}

В качестве регионального потока метана будем рассматривать массу $\mathrm{CH}_{4}$, перенесенную через границу «почва/атмосфера» на площади регионального масштаба в течение достаточного большого интервала времени (если перенос идет из почвы в атмосферу, то говорят об «эмиссии»; если в обратном направлении, то - об «отрицательной эмиссии» или «поглощении».). Из годовой цикличности биохимических процессов в почве (и вытекающей отсюда годовой цикличности динамики потока метана на границе «почва/атмосфера») естественным образом следует, что для полного представления о суммарном потоке необходимо измерять его величину, как минимум, в течение года. Именно такой интервал времени мы будем использовать ниже для расчетов.

Потоком массы называют массу, переносимую в единицу времени сквозь заданную поверхность. Для характеристики потока через отдельные элементы поверхности вводится понятие о поверхностной плотности потока (ППП) как о потоке через единицу поверхности [Филиппов, 1986, с. 6]. Очевидно,

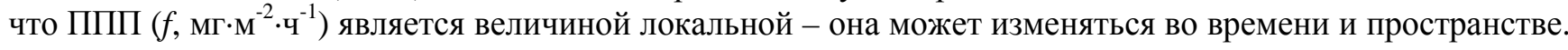
Тогда с математической точки зрения, региональный поток $(E$, мг):

$$
E=\int_{(S)}\left[\int_{0}^{T} f(x, y, t) d t\right] d S^{\prime},
$$

где $x, y$ - пространственные координаты, $t$ - время (внешний интеграл берется по площади региона $S$, а внутренний - по времени, на интервале $T=1$ год). Использование данной формулы и составляет основу любого метода оценки региональной эмиссии.

\footnotetext{
${ }^{3}$ Конечно, мы здесь очень упростили картину, а на самом деле кроме болот, рисовников и полигонов захоронения бытовых отходов необходимо учесть все другие существенные источники $\mathrm{CH}_{4}$ (крупный рогатый скот, утечки из газопроводов и т.д.).
} 


\section{Простейшая инвентаризация}

Покроем часть поверхности $(S)$ Земли метрической сеткой с шагами дискретизации $\Delta x_{k}, \Delta y_{j}$. Внутри ячейки поверхности $S_{k j}=\Delta x_{k} \cdot \Delta y_{j}$ все процессы считаются однородными. Базовой формой пространственного деления является задание равномерной сетки $\Delta x_{k}=$ const $_{1}, \Delta y_{j}=$ const $_{2}$. Но в зависимости от специфики рассматриваемого природного процесса структура регионального деления может быть связана с климатическими зонами, континентами, широтными поясами, социальноадминистративной структурой и природными зонами ${ }^{4}$ [Кондратьев и др., 2003, с. 50]. Поэтому далее мы будем рассматривать области любой формы, пронумерованные в произвольном порядке (для номера области оставим индекс $j$ ): $S_{j}$. Поскольку поверхностный интеграл аддитивен относительно областей интегрирования, то поток для всего региона $S$ может быть представлена как сумма потоков $E_{j}$ для составляющих его областей $S_{j}$ :

$$
E=\sum_{j} E_{j}, \quad \text { где } E_{j}=\int_{\left(S_{j}\right)}\left[\int_{0}^{T} f(x, y, t) d t\right] d S,
$$

В методе «простейшей инвентаризации» (далее - МеПИ) $E$ вычисляется приближенно по весьма простой формуле [Zelenev, 1996]:

$$
E=\sum_{i, j}\left(A_{i j} \cdot f_{i} \cdot T_{j}\right)
$$

где $A_{i j}$ - площадь $\left(\mathrm{M}^{2}\right)$, занимаемая $i$-м типом почв в $j$-ой области; $f_{i}-$ ППП (мг $\left.\cdot \mathrm{M}^{-2} \cdot \mathrm{ч}^{-1}\right)$, характерная для $i$ го типа почв; $T_{j}$ - продолжительность периода эмиссии (час), характерная для $j$-ой области. То, что эта формула с формально-математической точки зрения действительно представляет собой численную аппроксимацию интегралов из (\#2), показано в [Глаголев, 2007].

Пусть измерения выполнялись для каждого типа почв в каждой области. Обозначим через $f_{\text {in }}$ результат $n$-го измерения ППП, проведенного при работе на почве $i$-го типа. Тогда характерные величины $f_{i}$, входящие в вышеприведенную формулу, можно вычислить, тем или иным образом статистически обрабатывая (например, усредняя или используя медиану) измеренные значения $f_{\text {in }}$. Следовательно, МеПИ напрямую выражает $E_{i j}$ через результаты измерений $\left(f_{i n}\right)$.

Ниже мы подробно рассмотрим использование МеПИ, а сейчас для полноты картины упомянем еще о двух методах оценки регионального потока. Однако здесь их рассмотрение будет очень кратким в связи с тем, что они выходят за рамки, определенные сформулированной выше целью настоящей работы.

\section{Прямое математическое моделирование (решение прямой задачи)}

В предыдущем методе мы принимали, что ППП скачком меняется при переходе от одной достаточно большой пространственной области к другой, оставаясь постоянной внутри этих областей. На самом же деле, и внутри областей ППП изменяется в зависимости от ряда параметров внешней среды (например: температуры, уровня стояния и минерализации болотных вод, скорости их течения и др.). Если у нас есть математическая модель, связывающая $f$ с этими параметрами среды, то мы можем рассчитать значения $f$ для любой пространственной точки и в любой момент времени, после чего провести интегрирование по формуле (\#1).

Заметим, что с формально-математической точки зрения, изложенная выше «простейшая инвентаризация» является частным случаем прямого математического моделирования, причем простейшим частным случаем: предполагается, что $f$ const на достаточно больших интервалах времени и в достаточно протяженных областях пространства. Поскольку на самом деле это не так $(f$ изменяется во времени и пространстве!), то аппроксимация при помощи константы могла оказаться очень плохой, и привести к большой ошибке в интеграле $E$. Теперь же мы рассматриваем более точную аппроксимацию для $f$, что позволит получить более точное значение $E$.

В описываемом методе результаты экспериментальных измерений используются для того, чтобы определить численные значения эмпирических параметров. Т.е. подбираются такие величины параметров, чтобы расчеты по модели были как можно ближе к имеющимся экспериментальным данным. Если модель дает хорошее соответствие для достаточно большого числа достаточно хорошо

\footnotetext{
${ }^{4}$ Т.е. иногда сетку не вводят, а область $S$ разбивают на несколько подобластей $\left(S_{j}\right)$, соответствующих, например, климатическим зонам, или континентам, или широтным поясам и т.п. Тогда полагают, что все процессы считаются однородными не внутри ячейки сетки, а в пределах, соответственно, климатической зоны, или континента, или широтного пояса и т.п
} 
выбранных экспериментальных данных ${ }^{5}$, то можно надеяться, что она будет близка к реальности и во всех остальных случаях, для которых экспериментальная информация отсутствует.

В качестве примеров использования математических моделей поглощения метана почвами (для получения региональных и глобальных оценок) назовем [Potter et al., 1996; Ridgwell et al., 1999; Del Grosso et al., 2000; Curry, 2007; 2009]. Для полноты картины упомянем еще о моделях окисления, входящих как отдельный блок в модели эмиссии $\mathrm{CH}_{4}$ почвами. В этом случае, ставя перед собой целью описание в региональном масштабе эмиссии метана, авторы неизбежно (как промежуточный результат) получают и поглощение $\mathrm{CH}_{4}$. Сюда относится множество моделей, и мы перечислим лишь некоторые из них: модель для прибрежных осадков [Martens et al., 1998]; ECOSYS [Grant and Roulet, 2002]; модель Walter et al. [1996], в дальнейшем примененная к болотам в глобальном масштабе Walter et al. [2001] и еe модификации - PEATLAND [Van Huissteden et al., 2006] и PEATLAND-VU [Petrescu et al., 2008], а также «метановый» блок модели TEM [Zhuang et al., 2004] с его дальнейшем развитием в [Tang et al., 2010], наконец упомянем еще и модель LPJ-WHy (Lund-Potsdam-Jena dynamic global vegetation model for Wetland Hydrology) [Wania, 2007].

\section{Решение обратной задачи}

Очень кратко суть метода обратной задачи (далее - МO3) можно передать следующим образом. Пусть на поверхности существует $N$ источников или стоков некоторого газа, характеризующихся удельными потоками $F_{1}, F_{2}, \ldots, F_{N}$ (в дальнейшем для краткости будем говорить только о стоках, поскольку с формально-математической точки зрения источник также может рассматриваться как сток, взятый с обратным знаком). Для определенности будем рассматривать почвы различных типов, являющиеся стоками метана. Будем считать, что расположение стоков нам известно (на самом деле это не обязательное требование), но сами значения $F_{1}, F_{2}, \ldots, F_{\mathrm{N}}-$ не известны.

Предположим, что мы можем измерять концентрацию газа в $I$ точках с координатами $\left(x_{j}, y_{j}, z_{j}\right.$; $j=1,2, \ldots, I$ ). Это делается при помощи мачт (обычно на них организуется регулярный мониторинг, в результате которого имеется временной ряд динамики концентрации). Также возможно осуществлять эпизодический пробоотбор при помощи воздушных шаров, аэростатов и самолетов (см., например, [Fan et al., 1992; Bartlett et al., 2003; Глаголев и др., 2007]). В последнее время стало возможно получать информацию о концентрации $\mathrm{CH}_{4}$ непосредственно со спутников [Bergamaschi et al., 2007; Meirink et al., 2008], хотя пространственное разрешение и точность таких измерений, еще не слишком хороши. Итак, главное: для моментов времени $\tau_{i}$ в точках $\left(x_{j}, y_{j}, z_{j}\right)$ нам известны концентрации $C_{\mathrm{A}}\left(x_{j}, y_{j}, z_{j}, \tau_{i}\right)$.

Пусть, наконец, у нас есть математическая модель атмосферного переноса, позволяющая рассчитать концентрацию газа (в любой точке пространства для любого момента времени) по информации о параметрах атмосферы и о потоке газа на нижней границе области. Но подчеркнем, что этот поток нам не известен, зато известны концентрации внутри области и на ее границах (за исключением нижней). Тогда естественно предложить следующий способ определения потока: проведем расчеты по модели для различных наборов $F_{1}, F_{2}, \ldots, F_{N}$ и каждый раз будем сравнивать получающееся в результате вычислений поле концентраций внутри рассматриваемой области с реально измеренными значениями $C_{\mathrm{A}}\left(x_{j}, y_{j}, z_{j}, t_{i}\right)$ в точках пространства с координатами $\left(x_{j}, y_{j}, z_{j}\right)$ в моменты времени $t_{i}$. Если нам повезет угадать значения удельных потоков, близкие к истинным - тем, которые действительно сформировали в атмосфере измеренное поле концентраций, то (при условии достаточно высокой точности математической модели переноса) результаты расчета концентраций по модели окажутся очень близки к результатам реальных измерений концентраций в атмосфере. Эти-то величины удельных потоков, порождающие в модели поле концентраций, совпадающее (в пределах погрешности измерений) с реально наблюдаемым, и будут являться решением задачи.

Конечно, на самом деле при использовании метода обратного моделирования значения удельных потоков не угадываются, а ищутся при помощи специальных математических алгоритмов минимизации, хотя это и не единственный подход к решению задачи - в последние годы все шире начинают применяться так называемые сопряженные уравнения, не требующие численной минимизации. Подробнее о МО3 см., например, в [Mikaloff Fletcher et al., 2004; Bergamaschi et al., 2007; Meirink et al., 2008; Глаголев, 2010]. Однако, говоря о МО3, необходимо заметить, что в настоящее время он применяется, в основном, для идентификации источников, а не стоков $\mathrm{CH}_{4}$, что связано с техническими трудностями анализа малых концентраций метана. И это совершенно понятно - ведь при поглощении стоком любой мощности концентрация $\mathrm{CH}_{4}$ может в данной точке пространства изменяться в интервале

\footnotetext{
5 Под «достаточно хорошо выбранными» имеются в виду такие экспериментальные данные, которые получены в разных условиях окружающей среды. Если же, например, все измерения проведены при одной и той же температуре $t_{0}$, то, скорее всего, модель не будет давать правильных предсказаний при температурах, сильно отличающихся от $t_{\mathrm{o}}$.
} 
лишь от $\approx 1.7-1.8$ ppm (атмосферная концентрация [Christophersen et al., 2000; Del Grosso et al., 2000; Dutaur and Verchot, 2007]) до 0 ppm, тогда как при выделении - от 1.7-1.8 ppm до 1000000 ppm.

\section{РАЗЛИЧНЫЕ РЕАЛИЗАЦИИ МЕТОДА ПРОСТЕЙШЕЙ ИНВЕНТАРИЗАЦИИ}

\section{Поглощение метана почвами разных биомов - подход [Born et al., 1990]}

По-видимому, одной из первых работ (если не самой первой), посвященных возможности глобальной инвентаризации (табл. 1) окисления метана, была публикация [Born et al., 1990]. Основная идея авторов состояла в том, что в природе потребление метана в аэрируемых почвах определяется главным образом диффузией (что было обосновано экспериментально). А, например, потенциальная скорость процессов разложения, вызываемых микробами, имеет второстепенное значение (не была обнаружена корреляция поглощения $\mathrm{CH}_{4}$ с содержанием органического вещества в почве). Конечно, согласно законам химической (биохимической) кинетики на микробное (ферментативное) метанокисление в почвах влияют различные факторы:

- температура [King and Adamsen, 1992; Boeckx and van Cleemput, 1996; $\quad$ Boeckx et al., 1996; De Visscher et al., 2001];

- $\mathrm{pH}$ [Morishita et al., 2004],

- концентрации субстратов (т.е. метана [Bender and Conrad, 1993; Visvanathan et al., 1999] и кислорода, как через влажность [Christophersen et al., 2000; Kammann et al., 2000], определяющую его доступность, так и непосредственно - см., например, [Глаголев, 2006] и цитированную там литературу);

- концентрации ингибиторов (которыми являются, например, нитраты, нитриты, аммоний [Dunfield and Knowles, 1995; De Visscher et al., 1998], хлорид калия [Cai and Yan, 1999], $\mathrm{CS}_{2}, \mathrm{CH}_{3} \mathrm{SH}$ [Börjesson, 2001], летучие органические вещества [Chiemchaisri et al., 2000] и др. [Chan and Parkin, 2000]).

Однако влияние вышеперечисленных факторов будет проявляться в лабораторных условиях и в условиях небольших природных экосистем (впрочем, в последнем случае уже не всегда - см., например [Morishita et al., 2006]). Если же говорить о глобальном масштабе, то Dörr et al. [1993] не обнаружили корреляцию интенсивности потребления $\mathrm{CH}_{4}$ с температурой, $\mathrm{pH}$ и типом растительного покрова. Теоретическое обоснование этого было дано в [Глаголев, 2004], где объясняется, что при моделировании процессов образования и потребления метана в почве относительно постоянные факторы (такие, как, например, $\mathrm{pH}$ ) не нуждаются в подробном рассмотрении, поскольку, с эволюционной точки зрения, именно в силу их постоянства в данном местообитании должна была сформироваться микрофлора, оптимально приспособленная именно к этим условиям.

Таблица 1. Поглощение метана почвами различных биомов.

\begin{tabular}{|c|c|c|c|c|}
\hline \multirow[b]{2}{*}{ Tип экосистемы } & \multicolumn{2}{|c|}{ Площцадь $\left(\kappa \boldsymbol{M}^{2}\right)^{1)}$} & \multicolumn{2}{|c|}{ Поглощцение $\mathrm{CH}_{4}^{2)}$} \\
\hline & $\begin{array}{l}\text { (1 мupe [Born } \\
\text { et al., 1990] }\end{array}$ & в $P \Phi$ & $\begin{array}{c}\text { ППП }\left(\mathrm{m} \cdot \mathrm{\kappa m}^{-2} \cdot 20 \partial^{-1}\right) \\
\text { [Born et al., 1990] }\end{array}$ & $\begin{array}{c}\text { Поток в РФ } \\
(\text { Mm/год })\end{array}$ \\
\hline Леса бореального пояса (Boreal forest) & 12000000 & 5300829 & $0.695 \pm 0.605$ & $3.684 \pm 3.207$ \\
\hline Сезонных тропических лесов (Tropical seasonal forest) & 7500000 & 0 & $0.1 \pm 0.1$ & $0.000 \pm 0.000$ \\
\hline Степи и луга (Temperate grasslands) & 9000000 & 421993 & $0.101 \pm 0.099$ & $0.043 \pm 0.042$ \\
\hline Возделываемые земли (Cultivated land) & 14000000 & 2210112 & $0.101 \pm 0.099$ & $0.223 \pm 0.219$ \\
\hline Редколесья и кустарники (Woodland/Srubland) & 8000000 & 7165121 & $0.695 \pm 0.605$ & $4.980 \pm 4.335$ \\
\hline Леса умеренного пояса (Temperate forest) & 12000000 & 945721 & $0.695 \pm 0.605$ & $0.657 \pm 0.572$ \\
\hline Саванны (Savanna) & 15000000 & 0 & $0.445 \pm 0.255$ & $0.000 \pm 0.000$ \\
\hline Вода, лед, болота, городская застройка & н.Д. ${ }^{3)}$ & 890629 & 0 & $0.000 \pm 0.000$ \\
\hline & & & ВСЕГО: & $9.6 \pm 5.4$ \\
\hline
\end{tabular}

\footnotetext{
Примечания:

1) Количеством значащих цифр часто обозначают точность определения величин. В данном случае это, очевидно, не так.

${ }^{2)}$ Приведены значения среднего \pm разброс, т.е., например, запись «0.1 $\pm 0.1 »$ (для сезонных тропических лесов) означает, что они могут потреблять от $0(=0.1-0.1)$ до $0.2(=0.1+0.1) \mathrm{T}^{\circ} \mathrm{\kappa м}^{-2} \cdot$ год $^{-1}$.

${ }^{3)}$ Нет данных.
} 
Поглощение метана почвами разной структуры - подход [Dörr et al., 1993]

Подход, предложенный в [Born et al., 1990], развили далеe Dörr et al. [1993]. При измерениях в 15 км южнее г. Heidelberg эти исследователи обнаружили, что удельный поток метана $\left(j\right.$, мкмоль ${ }^{-2} \cdot$ час $\left.^{-1}\right)$ линейно зависит от коэффициента диффузии в почве $\left(D, \mathrm{~cm}^{2} \cdot c^{-1}\right)$ :

$$
j=a \cdot c \cdot D+b,
$$

где $\mathrm{e}^{6} a=-375 \pm 47$ мкмоль $\cdot \mathrm{M}^{-4}, b=-0.2 \pm 0.6$ мкмоль $\cdot \mathrm{M}^{-2} \cdot$ час $^{-1}, c=0.36 \mathrm{c} \cdot \mathrm{m}^{2} \cdot \mathrm{cm}^{-2} \cdot$ час $^{-1} ; \mathrm{R}^{2}=0.7$. Ранее Born et al. [1990] говорили о нелинейной зависимости $j(D)$, хотя и не дали ее формулу. Однако в работе [Born et al., 1990] охвачен только интервал $D$ от 0.001 до $0.031 \mathrm{~cm}^{2} \cdot c^{-1}$, тогда как в [Dörr et al., 1993] - от 0.013 до $0.053 \mathrm{~cm}^{2} \cdot \mathrm{c}^{-1}$. По суммарному массиву данных (составленному из данных обеих только что процитированных работ) мы нашли для зависимости (\#3) следующие коэффициенты: $a=-407 \pm 30$ мкмоль $\cdot \mathrm{M}^{-4}, b=-0.351 \pm 0.311$ мкмоль $\cdot \mathrm{M}^{-2} \cdot$ час $^{-1}$ (при этом $\mathrm{R}^{2}=0.8123$ ). Разброс измеренных значений довольно велик, поэтому использование вместо (\#3) нелинейных зависимостей почти не дает уменьшения $\mathrm{R}^{2}$ по сравнению с линейной (например, для квадратичного многочлена $\mathrm{R}^{2}=0.8124$ ). Более того, как видим из оценки погрешности коэффициента $b$, в случае использования только массива Dörr et al. [1993] этот коэффициент статистически не значим, да и в случае суммарного массива (из [Born et al., 1990] и [Dörr et al., 1993]) его значимость весьма низкая, следовательно, напротив, нужно не усложнять, а упрощать используемую регрессионную модель - отбросить (обнулить) коэффициент $b$. Отбрасывание этого коэффициента соответствует и физическому смыслу. Действительно, согласно (\#3), удельный поток при нулевой диффузии равен $b$, но при нулевой диффузии кислород вообще не будет поступать в почву и окисление должно быть нулевым ${ }^{7}$, следовательно, по физическому смыслу должно быть $b=0$ мкмоль м $^{-2} \cdot$ час $^{-1}$. Наилучшая линейная зависимость, удовлетворяющая (в смысле наименьших квадратов) этому ограничению, имеет $a=-379$ мкмоль ${ }^{-4}$ (при этом $\mathrm{R}^{2}=0.8069$ ).

Теоретическое объяснение данному подходу дал Striegl [1993]. Согласно ему, транспорт газов из атмосферы в почву и из почвы в атмосферу определяется главным образом диффузией. Причиной поглощения метана поверхностью автоморфных почв является его потребление бактериямиметанотрофами в верхнем слое почвы, имеющем толщину в несколько сантиметров. При этом способность метанотрофов к потреблению метана обычно превышает пропускную способность диффузионного механизма транспорта. Таким образом, максимальная скорость поглощения почвой метана из атмосферы лимитируется именно диффузией. Позднее Potter et al. [1996] подтвердили, что главным фактором, ограничивающим окисление метана в большинстве почв, является именно диффузия атмосферного $\mathrm{CH}_{4}$ в них.

Для упрощения процедуры региональной и глобальной оценки Dörr et al. [1993] разбили почвы на три основных структурных класса (“Coarse”, "Medium”, “Fine”), которым соответствовали определенные значения коэффициента диффузии и скорости поглощения $\mathrm{CH}_{4}$ (табл. 2). Распределение почв этих классов по поверхности Земли задавалось ими в соответствии с глобальной базой данных почвенных типов NASA-GISS. На основе вышеуказанной информации была построена цифровая карта поглощения $\mathrm{CH}_{4}$ (табл. 3).

К сожалению, эта карта содержит существенное противоречие, которое ставит под сомнение возможность ее использования. Действительно, в [Dörr et al., 1993] она (Fig. 10) имеет название «Illustration of the soil texture parameterization of methane uptake by aerated soils». Таким образом, казалось бы, речь идет не столько об интенсивности поглощения $\mathrm{CH}_{4}$, сколько о распределении почв различных структурных классов по поверхности Земли. Но условные обозначения на карте (данные нами в Примечании к табл. 3) поясняются именно в терминах поглощения метана («no methane uptake», «low methane uptake», «medium methane uptake», «high methane uptake»). Таким образом, становится очевидным, что это, все-таки, карта поглощения метана (быть может, не очень удачно названная авторами). Однако в тексте оригинальной статьи (р. 712: 2-ой и 3-ий абзацы сверху) совершенно ясно написано, что по структурным классам определялось как бы потенциальное поглощение метана, а для

\footnotetext{
6 Значения и размерности $a$ и $b$ взяты нами из Dörr et al. [1993, p. 706]. Но на Figure 6 Dörr et al. [1993, p. 705] приводят $a=-375 \pm 47$ мкмоль $\mathrm{m}^{-2}$. Тогда, конечно, $c=0.36 \mathrm{c} \cdot \mathrm{cm}^{-2} \cdot$ час ${ }^{-1}$. Вообще говоря, в оригинальной работе коэффициент $c$ отсутствует. Но тогда у авторов нарушается равенство размерностей в правой и левой частях (\#3). Чтобы избежать этой проблемы, мы и ввели коэффициент $c$. Если читатель хочет получить представление о том, что в точности написано в [Dörr et al., 1993], то он должен положить $c=1$. Если же он хочет корректно провести расчеты, то ему следует использовать $c=0.36$.

${ }^{7}$ Конечно, коэффициент диффузии в реальности никогда не обращается строго в ноль, но в определенных условиях (например, при замерзании верхнего слоя почвы, насыщенной водой) он становится столь мал, что действительно может рассматриваться стремящимся к нулю.
} 
перехода от потенциального поглощения (П) к актуальному (А) использовалось простое правило: $\mathrm{A}=0$ для пустынь и болот, а для всех остальных типов экосистем $\mathrm{A}=$ П. Следовательно, если бы речь шла действительно о карте поглощения $\mathrm{CH}_{4}$ (актуального), то на месте, например, Сахары, мы должны были бы видеть нули, но там стоят единицы. Может быть перед нами карта потенциального поглощения метана? Нет! Ведь в этом случае на месте Сахары, покрытой песком, должны находиться тройки!!! Остается предположить, что, все-таки, перед нами карта актуального поглощения, однако в каждую ячейку сетки этой карты $\left(8^{\circ}\right.$ с.ш. $\times 10^{\circ}$ в.д.), расположенную, например, в районе Сахары, попадали не только почвы пустынь, но и какие-то иные песчаные почвы, которые локально обеспечивали существенное поглощение $\mathrm{CH}_{4}$ (т.е. локально должны были бы обозначаться тройками), следовательно, при усреднении по всей ячейке, большую часть площади которой занимали пустыни с нулевым поглощением $\mathrm{CH}_{4}$, получалось незначительное потребление метана (хотя и не нулевое!). Однако еще более странно то, что авторы четко указывают: болота и пустыни (в отличие от иных территорий, сильно, средне или слабо потребляющих метан) на карте не обозначены («Low methane fluxes are indicated by open circles, high fluxes by filled circles, and medium fluxes by stars. Natural wetlands and desert regions have no signature)», но мы ясно видим обозначения той или иной интенсивности потребления $\mathrm{CH}_{4}$, например, на месте Сахары (пустыни!) и Западной Сибири (болота!).

Таблица 2. Удельные скорости поглощения $\mathrm{CH}_{4}$ почвами разных структурных классов.

\begin{tabular}{|c|c|c|c|c|c|c|c|}
\hline \multicolumn{2}{|r|}{ Структурный класс } & \multicolumn{2}{|c|}{ Содержание (\%) } & \multirow{2}{*}{\multicolumn{3}{|c|}{ Поглощение $\mathrm{CH}_{4}^{2)}\left(2 \cdot \mathrm{M}^{-2} \cdot 2 о \partial^{-1}\right)$}} & \multirow{4}{*}{$\begin{array}{c}\text { Коэффициент } \\
\text { оиффузии } \\
\left(\text { c. }^{2} \cdot c^{-1}\right) \text { no } \\
\text { [Dörr et al., 1993] }\end{array}$} \\
\hline \multirow{3}{*}{ № } & \multirow{3}{*}{ Название } & песка & глинь & & & & \\
\hline & & \multirow{2}{*}{\multicolumn{3}{|c|}{ no [Dörr et al., 1993] }} & \multicolumn{2}{|c|}{ no [Dutaur and Verchot, 2007] } & \\
\hline & & & & & среднее & $\mathrm{CKO}^{6)}$ & \\
\hline 1 & Coarse & $\geq 65$ & $\leq 18$ & $0.52 \pm 0.39$ & 0.42 & 1.45 & $0.034 \pm 0.022$ \\
\hline 2 & Medium & $\leq 65$ & $\leq 18$ & $0.16 \pm 0.14$ & 0.33 & 1.34 & $0.012 \pm 0.008$ \\
\hline 3 & Fine & & $\geq 35$ & $0.07 \pm 0.04$ & 0.20 & 0.42 & $0.004 \pm 0.002$ \\
\hline 4 & Coarse-Medium & н.д. & н.д. & $0.34 \pm 0.27^{3}$ & 0.38 & 1.40 & н.Д. \\
\hline 5 & Coarse-Fine & Н.д. & н.Д. & $0.29 \pm 0.22$ & \multicolumn{2}{|c|}{ н.д. } & н.Д. \\
\hline 6 & Medium-Fine & н.д. & н.д. & $0.12 \pm 0.09$ & 0.27 & 0.88 & н.Д. \\
\hline 7 & Coarse-Medium-Fine & н.д. & н.д. & 0.25 & \multicolumn{2}{|c|}{ н.д. } & н.д. \\
\hline 8 & Organic $^{1)}$ (бесструктурные) & н.д. & н.д. & 0.25 & 0.31 & 0.96 & н.д. \\
\hline 9 & Land-Ice & Н.д. & н.д. & 0 & \multicolumn{2}{|c|}{ н.д. } & н.Д. \\
\hline 0 & Water & н.Д. & н.Д. & 0 & \multicolumn{2}{|c|}{ н.д. } & $0.00000328^{4)}$ \\
\hline
\end{tabular}

Примечания.

1) Здесь возникает некоторое противоречие с правилом расчета актуального потребления метана, в котором принимается, что болота характеризуются нулевым поглощением. Но ведь органические почвы - это и есть, в частности, почвы болот. Однако в данной таблице они характеризуются существенным поглощением $\mathrm{CH}_{4}$.

2) Для классов 1-3 авторы приводят экспериментальные данные, снабжая их погрешностью. Для остальных классов погрешность не приводилась, поскольку для классов 4-7 принимались средние арифметические значения, а для 9 и 0 назначались умозрительно. При отсутствии погрешности в оригинальной статье для промежуточного структурного класса мы вычисляли ее как среднее арифметическое погрешностей удельных потоков исходных структурных классов.

3) Авторы дают для «Coarse-Medium» значение 0.24, однако это, по-видимому, описка. Ведь если строго следовать сформулированному ими правилу расчета удельных потоков для смешанных структурных классов как среднему арифметическому удельных потоков для основных классов, то получим: $(0.52+0.16) / 2=0.34$. При этом, значение 0.34 становится вполне естественным в сравнении со значением 0.25 для «Сoarse-Medium-Fine». Действительно, добавление слабо потребляющего метан «Fine» (0.07) к относительно хорошо потребляющему «Coarse-Medium» (0.34) приводит к снижению интенсивности поглощения $\mathrm{CH}_{4}$ - значению 0.25 для «Coarse-Medium-Fine». А если придерживаться значения 0.24, имеющегося в оригинальной работе, то получится, что добавление слабо потребляющего метан «Fine» к «Соаrse-Mеdium» приводит к небольшому увеличению интенсивности поглощения, что, конечно, абсурдно. Погрешность удельного потока для «Coarse-Medium» вычислена нами как среднее арифметическое погрешностей удельных потоков для «Соагse» и «Medium».

4) Мы приводим здесь значение коэффициента диффузии в воде при $10^{\circ} \mathrm{C}$ из [Елецкий, 1991]. Некоторые значения при других температурах, а также интерполяционную кривую для любых температур от 0 до $60^{\circ} \mathrm{C}$ см. в [Глаголев и Смагин, 2005, с. 114, 116-117].

5) Более подробную классификацию см. в табл. 5.

6) В оригинальной работе дана дисперсия (variance), но мы решили привести более привычное значение - среднее квадратическое отклонение (равное квадратному корню из дисперсии [Королюк с соавт., 1985, с. 29]).

7) К сожалению, авторы в своей сводной таблице явно не указывают - какая характеристика погрешности приводится ими в записи вида «среднее \pm погрешность», однако при обсуждения результатов этой таблицы в тексте («Тhе rather large standard deviation of the average permeability and methane fluxes are supposedly due to the small number of samples in each texture class...») используется термин «стандартное отклонение», откуда можно предположить, что и в таблице были даны стандартные отклонения. 
Таблица 3. Глобальное поглощение метана почвами, согласно [Dörr et al., 1993].

\begin{tabular}{|c|c|c|c|c|c|c|c|c|c|c|c|c|c|c|c|c|c|c|c|c|c|c|c|c|c|c|c|c|c|c|c|c|c|c|c|c|}
\hline \multirow{2}{*}{$\begin{array}{c}\text { Север- } \\
\text { ная } \\
\text { широта }\end{array}$} & \multicolumn{36}{|c|}{ Долгота $\left(^{\circ}\right)$} \\
\hline & \begin{tabular}{|l|}
180 \\
175
\end{tabular} & \begin{tabular}{|l|}
175 \\
165
\end{tabular} & $165 \mid$ & $\begin{array}{l}155 \\
145\end{array}$ & 145 & \begin{tabular}{|l|}
135 \\
125 \\
\end{tabular} & \begin{tabular}{|l|}
125 \\
115
\end{tabular} & $\begin{array}{l}115 \\
105\end{array}$ & 105 & & & & \begin{tabular}{|l|}
65 \\
55
\end{tabular} & & \begin{tabular}{|l|}
45 \\
35
\end{tabular} & & & $\begin{array}{c}15 \\
5\end{array}$ & & & \begin{tabular}{|l|}
15 \\
25
\end{tabular} & & & & $\begin{array}{l}55 \\
65\end{array}$ & & & \begin{tabular}{l|l}
85 & 9 \\
95 & 10
\end{tabular} & & \begin{tabular}{l|l}
05 & 11 \\
15 & 12
\end{tabular} & \begin{tabular}{l|l|}
5 & 125 \\
5 & 135
\end{tabular} & 135 & \begin{tabular}{|l|}
145 \\
155
\end{tabular} & $\begin{array}{l}155 \\
165\end{array}$ & 165 & 175 \\
\hline $88 \div 90$ & 0 & 0 & 0 & 0 & 0 & 0 & 0 & 0 & 0 & 0 & 0 & 0 & 0 & 0 & 0 & 0 & 0 & 0 & 0 & 0 & 0 & 0 & 0 & 0 & 0 & \begin{tabular}{l|l}
0 \\
\end{tabular} & \begin{tabular}{l|l}
0 & \\
\end{tabular} & \begin{tabular}{l|l}
0 & 0 \\
\end{tabular} & \begin{tabular}{l|l}
0 & 0 \\
\end{tabular} & \begin{tabular}{l|l}
0 & 0 \\
\end{tabular} & 0 & 0 & 0 & 0 & 0 & 0 \\
\hline $88 \div 88$ & 0 & 0 & 0 & 0 & 0 & 0 & 0 & 0 & 0 & 0 & 0 & 0 & 0 & 0 & 0 & 0 & 0 & 0 & 0 & 0 & 0 & 0 & 0 & 0 & 0 & 0 & 0 & 0 & 0 & 0 & 0 & 0 & 0 & 0 & 0 & 0 \\
\hline $72 \div 80$ & 0 & 0 & 0 & 0 & 0 & 0 & 0 & 1 & 1 & 0 & 0 & 0 & 0 & 0 & 0 & 0 & 0 & 0 & 0 & 0 & 0 & 0 & 0 & 0 & 0 & 0 & 0 & 1 & 1 & 0 & 0 & 0 & 0 & 0 & 0 & 0 \\
\hline $64 \div 72$ & 1 & 0 & 2 & 2 & 1 & 2 & 2 & 2 & 1 & 1 & 1 & 1 & 0 & 0 & 0 & 0 & 0 & 0 & 0 & 0 & 1 & 1 & 1 & 1 & 1 & 1 & 2 & 2 & 2 & 3 & 2 & 2 & 2 & 2 & 2 & 2 \\
\hline $56 \div 64$ & 0 & 0 & 1 & 1 & 1 & 1 & 3 & 2 & 1 & 1 & 0 & 1 & 0 & 0 & 0 & 0 & 0 & 0 & 0 & 1 & 1 & 2 & 2 & 2 & 2 & 2 & 2 & 2 & 2 & 3 & 3 & 2 & 2 & 2 & 1 & 0 \\
\hline $48 \div 56$ & 0 & 0 & 0 & 0 & 0 & 1 & 2 & 2 & 3 & 2 & 1 & 1 & 1 & 0 & 0 & 0 & 0 & 0 & 1 & 2 & 2 & 2 & 2 & 2 & 3 & 3 & 3 & 3 & 3 & 3 & 2 & 1 & 0 & 1 & 0 & 0 \\
\hline $40 \div 48$ & 0 & 0 & 0 & 0 & 0 & 0 & 2 & 2 & 2 & 2 & 2 & 1 & 0 & 0 & 0 & 0 & 0 & 0 & 2 & 2 & 2 & 2 & 2 & 2 & 3 & 3 & 2 & 2 & 2 & 3 & 2 & 1 & 0 & 0 & 0 & 0 \\
\hline $32 \div 40$ & 0 & 0 & 0 & 0 & 0 & 0 & 1 & 2 & 2 & 3 & 2 & 0 & 0 & 0 & 0 & 0 & 0 & 1 & 2 & 1 & 1 & 1 & 3 & 2 & 2 & 2 & 2 & 2 & 2 & 2 & 1 & 1 & 0 & 0 & 0 & 0 \\
\hline $24 \div 32$ & 0 & 0 & 0 & 0 & 0 & 0 & 0 & 2 & 2 & 1 & 0 & 0 & 0 & 0 & 0 & 0 & 0 & 1 & 2 & 2 & 2 & 1 & 2 & 2 & 2 & 2 & 2 & 2 & 3 & 2 & 0 & 0 & 0 & 0 & 0 & 0 \\
\hline $16 \div 24$ & 0 & 0 & 0 & 0 & 0 & 0 & 0 & 0 & 2 & 1 & 0 & 0 & 0 & 0 & 0 & 0 & 0 & 1 & 1 & 1 & 1 & 1 & 1 & 2 & 0 & 1 & 3 & 1 & 2 & 1 & 0 & 0 & 0 & 0 & 0 & 0 \\
\hline $8 \div 16$ & 0 & 0 & 0 & 0 & 0 & 0 & 0 & 0 & 0 & 1 & 1 & 1 & 0 & 0 & 0 & 0 & 0 & 2 & 1 & 1 & 2 & 2 & 3 & 1 & 0 & 0 & 1 & 0 & 1 & 0 & 0 & 0 & 0 & 0 & 0 & 0 \\
\hline $0 \div 8$ & 0 & 0 & 0 & 0 & 0 & 0 & 0 & 0 & 0 & 0 & 1 & 3 & 3 & 1 & 0 & 0 & 0 & 1 & 1 & 2 & 2 & 3 & 3 & 1 & 0 & 0 & 0 & 0 & 1 & 1 & 0 & 0 & 0 & 0 & 0 & 0 \\
\hline$-8 \div 0$ & 0 & 0 & 0 & 0 & 0 & 0 & 0 & 0 & 0 & 0 & 2 & 3 & 3 & 3 & 2 & 0 & 0 & 0 & 0 & 1 & 2 & 3 & 1 & 0 & 0 & 0 & 0 & 0 & 1 & 1 & 0 & 2 & 0 & 0 & 0 & 0 \\
\hline$-16 \div-8$ & 0 & 0 & 0 & 0 & 0 & 0 & 0 & 0 & 0 & 0 & 0 & 3 & 3 & 3 & 2 & 0 & 0 & 0 & 0 & 0 & 2 & 3 & 2 & 0 & 0 & 0 & 0 & 0 & 0 & 0 & 1 & 1 & 0 & 0 & 0 & 0 \\
\hline$-24 \div-16$ & 0 & 0 & 0 & 0 & 0 & 0 & 0 & 0 & 0 & 0 & 0 & 1 & 3 & 3 & 2 & 0 & 0 & 0 & 0 & 0 & 1 & 2 & 1 & 1 & 0 & 0 & 0 & 0 & 0 & 0 & 2 & 2 & 1 & 0 & 0 & 0 \\
\hline$-32 \div-24$ & 0 & 0 & 0 & 0 & 0 & 0 & 0 & 0 & 0 & 0 & 0 & 1 & 3 & 2 & 0 & 0 & 0 & 0 & 0 & 0 & 1 & 2 & 0 & 0 & 0 & 0 & 0 & 0 & 0 & 2 & 2 & 2 & 2 & 0 & 0 & 0 \\
\hline$-40 \div-32$ & 0 & 0 & 0 & 0 & 0 & 0 & 0 & 0 & 0 & 0 & 0 & 2 & 2 & 0 & 0 & 0 & 0 & 0 & 0 & 0 & 0 & 0 & 0 & 0 & 0 & 0 & 0 & 0 & 0 & 0 & 0 & 1 & 1 & 0 & 0 & 0 \\
\hline$-48 \div-40$ & 0 & 0 & 0 & 0 & 0 & 0 & 0 & 0 & 0 & 0 & 0 & 2 & 0 & 0 & 0 & 0 & 0 & 0 & 0 & 0 & 0 & 0 & 0 & 0 & 0 & 0 & 0 & 0 & 0 & 0 & 0 & 0 & 0 & 0 & 0 & 0 \\
\hline$-66 \div-48$ & 0 & 0 & 0 & 0 & 0 & 0 & 0 & 0 & 0 & 0 & 0 & 1 & 0 & 0 & 0 & 0 & 0 & 0 & 0 & 0 & 0 & 0 & 0 & 0 & 0 & 0 & 0 & 0 & 0 & 0 & 0 & 0 & 0 & 0 & 0 & 0 \\
\hline$-64 \div-56$ & 0 & 0 & 0 & 0 & 0 & 0 & 0 & 0 & 0 & 0 & 0 & 0 & 0 & 0 & 0 & 0 & 0 & 0 & 0 & 0 & 0 & 0 & 0 & 0 & 0 & 0 & 0 & 0 & 0 & 0 & 0 & 0 & 0 & 0 & 0 & 0 \\
\hline$-72 \div-64$ & 0 & 0 & 0 & 0 & 0 & 0 & 0 & 0 & 0 & 0 & 0 & 0 & 0 & 0 & 0 & 0 & 0 & 0 & 0 & 0 & 0 & 0 & 0 & 0 & 0 & 0 & 0 & 0 & 0 & 0 & 0 & 0 & 0 & 0 & 0 & 0 \\
\hline$-80 \div-72$ & 0 & 0 & 0 & 0 & 0 & 0 & 0 & 0 & 0 & 0 & 0 & 0 & 0 & 0 & 0 & 0 & 0 & 0 & 0 & 0 & 0 & 0 & 0 & 0 & 0 & 0 & 0 & 0 & 0 & 0 & 0 & 0 & 0 & 0 & 0 & 0 \\
\hline$-88 \div-80$ & 0 & 0 & 0 & 0 & 0 & 0 & 0 & 0 & 0 & 0 & 0 & 0 & 0 & 0 & 0 & 0 & 0 & 0 & 0 & 0 & 0 & 0 & 0 & 0 & 0 & 0 & 0 & 0 & 0 & 0 & 0 & 0 & 0 & 0 & 0 & 0 \\
\hline$-90 \div-88$ & 0 & 0 & 0 & 0 & 0 & 0 & \begin{tabular}{|l|l|}
0 \\
\end{tabular} & 0 & 0 & 0 & 0 & 0 & 0 & \begin{tabular}{|l|l|}
0 \\
\end{tabular} & 0 & 0 & 0 & 0 & 0 & \begin{tabular}{|l|}
0 \\
\end{tabular} & 0 & 0 & 0 & \begin{tabular}{|l|}
0 \\
\end{tabular} & 0 & & & \begin{tabular}{l|l}
0 & 0 \\
\end{tabular} & \begin{tabular}{l|l}
0 & 0 \\
\end{tabular} & \begin{tabular}{l|l}
0 & 0 \\
\end{tabular} & 0 & 0 & \begin{tabular}{|l|}
0 \\
\end{tabular} & 0 & 0 & \\
\hline
\end{tabular}

Примечание. 0 - потребление метана отсутствует; 1 - слабое потребление метана; 2 - среднее потребление метана; 3 - высокое потребление метана (к сожалению, авторы не приводят численные значения для этих классов).

Таблица 4. Поглощение метана почвами различных биомов ${ }^{9)}$, согласно [Dutaur and Verchot, 2007].

\begin{tabular}{|c|c|c|c|c|c|c|}
\hline \multirow[b]{2}{*}{ Tип экосистемы } & \multirow{2}{*}{$\begin{array}{c}\text { Изучено } \\
\text { точек }\end{array}$} & \multicolumn{2}{|c|}{ Площадь $\left(\kappa м^{2}\right)$} & \multicolumn{3}{|c|}{ Поглощение $\mathrm{CH}_{4}$} \\
\hline & & в мире & в $\boldsymbol{P} \Phi^{8)}$ & $\begin{array}{c}\text { ППП } \\
\left(m \cdot \kappa \boldsymbol{m}^{-2} \cdot 20 \partial^{-1}\right)\end{array}$ & $\begin{array}{c}\boldsymbol{C K O ^ { 7 ) }} \\
\left(\boldsymbol{m} \cdot \boldsymbol{\kappa} \boldsymbol{M}^{-2} \cdot 20 \partial^{-1}\right)\end{array}$ & $\begin{array}{c}\text { Поток в РФ } \\
(\mathrm{Mm} / \text { год })\end{array}$ \\
\hline Тундра (Tundra) & 11 & 9410000 & 5240436 & 0.149 & 0.235 & $0.781 \pm 1.232$ \\
\hline Лесотундра + леса бореального пояса & 51 & $23490000^{1)}$ & 7225514 & 0.264 & 0.284 & $1.908 \pm 2.052$ \\
\hline Пустыни & 5 & $21920000^{2}$ & 166651 & 0.110 & 0.101 & $0.018 \pm 0.017$ \\
\hline Степи и луга (Grasslands) & 29 & 2610000 & 255342 & 0.232 & 0.171 & $0.059 \pm 0.044$ \\
\hline Возделываемые земли (Cultivation) & $47^{3)}$ & 24790000 & 2210112 & 0.123 & 0.110 & $0.272 \pm 0.243$ \\
\hline Чапараль (Chaparral) & 3 & 2170000 & 0 & 0.225 & 0.073 & $0.000 \pm 0.000$ \\
\hline Леса умеренного пояса & 92 & $6760000^{4}$ & 945721 & 0.57 & 0.561 & $0.539 \pm 0.531$ \\
\hline Тропические степи и саванны & 18 & $19480000^{5}$ & 0 & 0.149 & 0.124 & $0.000 \pm 0.000$ \\
\hline Тропические леса & 62 & $20000000^{6}$ & 0 & 0.333 & 0.220 & $0.000 \pm 0.000$ \\
\hline ВСЕГО & 318 & 130630000 & & & & $3.6 \pm 2.5$ \\
\hline
\end{tabular}

Примечания:

${ }^{1)}$ Площадь лесотундры (Forest tundra) составляет 8.18·10 ${ }^{6}$ км², а лесов бореального пояса (Boreal forest) $-15.31 \cdot 10^{6}$ км².

${ }^{2)}$ Площадь холодных пустынь (Cool desert) составляет 2.63·10 км $^{2}$, горячих пустынь (Hot desert) $-19.29 \cdot 10^{6}$ км$^{2}$.

${ }^{3)}$ В бореальном поясе было расположено 3 исследовательских сайта, в тропическом - 6 сайтов, в умеренном - 38 .

${ }^{4)}$ Площадь холодных лесов умеренного пояса (Cool temperate forest) составляет $5.07 \cdot 10^{6} \mathrm{\kappa м}^{2}$, а теплых лесов умеренного пояса (Warm temperate forest) $-1.69 \cdot 10^{6} \mathrm{\kappa м}^{2}$.

${ }^{5)}$ Площадь тропических степей (Tropical semiarid steppe) составляет $7.98 \cdot 10^{6}$ км$^{2}$, а тропических саванн (Tropical savanna) $11.50 \cdot 10^{6} \mathrm{\kappa м}^{2}$.

${ }^{6)}$ Площадь сезонных тропических лесов (Tropical seasonal forest) составляет $12.83 \cdot 10^{6}$ км$^{2}$, а тропических дождевых лесов (Tropical rain forest) $-7.17 \cdot 10^{6} \mathrm{Kм}^{2}$.

${ }^{7)}$ См. Примечание 6 к табл. 2.

${ }^{8)}$ Результаты наших расчетов (среднее \pm СКО).

${ }^{9)} \mathrm{B}$ таблице перечислены биомы, характеризующиеся ненулевым поглощением $\mathrm{CH}_{4}$. Для экосистем литосолей поглощение принято равным нулю [Dutaur and Verchot, 2007]. Литосоль (lithosol) - обобщенный термин, используемый для азональных почв с неполным солумом или со слабо выраженной морфологией, сформировавшихся из недавно и недостаточно выветрелой породы. Согласно Легенде FAO (1975), литосоль - это почва, ограниченная на глубине менее 10 см плотной, твердой и сплошной породой, а согласно D'Hoore, литосоль - это почва с крайне слабой дифференциацией генетических горизонтов, в которой твердая и сплошная материнская порода залегает на глубине менее 30 см. Солум (от лат. solum основа) - совокупность горизонтов А и В одного профиля; иногда включает слои на уровне горизонта С, если их генетические свойства связаны с развитием верхних горизонтов [Лозе и Матье, 1998, с. 168, 308]. 


\section{Поглощение метана почвами разной структуры в разных биомах}

В работе [Dutaur and Verchot, 2007] проанализировано более 120 публикаций, содержащих результаты полевых измерений поглощения $\mathrm{CH}_{4}$ в экосистемах различных типов. По материалам этих публикаций составлена база данных, содержащая ряд параметров, характеризующих факторы, определяющие интенсивность поглощения метана (климатическая зона, тип экосистемы, широта, среднегодовое количество осадков, среднегодовая температура, структура почвы). Регрессионный анализ, проведенный по непрерывным переменным из числа вышеперечисленных (т.е. по широте, температуре и количеству осадков) не выявил значимых взаимосвязей (соответственно, $\mathrm{R}^{2}=0.01,0.02$ и 0.03). Разбиение данных на классы в соответствии со значениями дискретных переменных («климатическая зона», «тип экосистемы» и «структура почвы») обеспечило лучшее качество предсказаний $\left(\mathrm{R}^{2}=0.29, \mathrm{P}<0.0001\right)$. В результате авторами каждому биому было приписано некоторое характерное поглощение метана (табл. 4).

\section{ОБСУЖДЕНИЕ ПРОСТЕЙШИХ ГЛОБАЛЬНЫХ ИНВЕНТАРИЗАЦИЙ}

\section{Сравнение инвентаризаций}

К сожалению, сравнение глобальных инвентаризаций Born et al. [1990] и Dutaur and Verchot [2007] по отдельным типам экосистем не всегда возможно, поскольку у данных авторов площади одинаково называемых ими экосистем в некоторых случаях сильно различаются. Например, согласно [Born et al. 1990] «Возделываемые земли» занимают площадь $14 \cdot 10^{6} \mathrm{kм}^{2}$ (табл. 1) а согласно [Dutaur and Verchot, 2007] - почти $25 \cdot 10^{6}$ км$^{2}$ (табл. 4). Поскольку в каждой стране существуют данные статистического учета сельскохозяйственных угодий, то, казалось бы, достаточно точная оценка их площади не должна была вызывать особых трудностей. В связи с этим то, что кто-то из цитированных авторов ошибся при подсчете площади возделываемых земель почти в 2 раза, кажется нам менее вероятным, чем иные объяснения: возможно, в [Born et al. 1990] к «Возделываемым землям» относится меньше видов экосистем, чем в [Dutaur and Verchot, 2007], либо за 17 лет, прошедших между публикациями рассматриваемых работ, в мире существенно увеличились площади возделываемых земель. Из сравнения табл. 1 и 4 видно, что значительные расхождения в площадях наблюдаются практически для всех тех биомов, которые рассмотренны обоими авторскими коллективами. Тем не менее, мы попытаемся дать сравнительный анализ этих работ.

Dörr et al. [1993] считают, что их подход дает более реалистичную картину (табл. 3), чем подход Born et al. [1990], учитывающий только тип растительности. Позднее Dutaur and Verchot [2007], с одной стороны, подтвердили идею, высказанную в [Dörr et al., 1993] - действительно, структура почвы может быть хорошим предиктором интенсивности потребления метана. Однако, с другой стороны, наибольшая доля вариации оказалась связана с переменной «тип экосистемы», так что наилучшим предиктором, согласно их исследованию, является именно она, что вполне согласуется с [Born et al., 1990].

Пожалуй, слабым местом ранних работ ([Born et al., 1990; Dörr et al., 1993]) является то, что экспериментально исследовались почти одни только лесные почвы (не говоря уже о том, что почти все пробы почв Dörr et al. [1993] брали на территории Центральной Европы, a Born et al. [1990] - вообще лишь в Западной Германии). Отсюда следует, что, к сожалению, основная идея (об отсутствии влияния на поглощение $\mathrm{CH}_{4}$ температуры и других факторов, кроме структуры почвы) вообще может оказаться неверной. Действительно, на приводимом в ее подтверждение рисунке, Dörr et al. [1993] ограничиваются интервалом температур примерно от 2.7 до $18.9^{\circ} \mathrm{C}$, утверждая, что корреляция между температурой и потоком незначительна (проведенный нами регрессионный анализ по этим данным дал уравнение с $\left.\mathrm{R}^{2} \approx 0.26\right)$. Излишне говорить, что такой относительно небольшой температурный интервал явился следствием специфических объектов исследования. Впрочем, Born et al. [1990] обнаруживали достаточно хорошую корреляцию между поглощением $\mathrm{CH}_{4}$ и температурой почвы на интервале всего лишь от 4 до $16^{\circ} \mathrm{C}$. Однако они ею пренебрегали на том основании, что величина $Q_{10}$ составляла только 1.5 , в то время как для $\mathrm{CO}_{2} Q_{10}=4.3$ при исследовании той же самой почвы в том же самом температурном интервале. Однако такая аргументация не выглядит убедительной. Дело в том, что из-за существенно разной растворимости $\mathrm{CO}_{2}$ и $\mathrm{CH}_{4}$ в почвенной воде и адсорбции на почвенных частицах кажущееся значение $Q_{10}$ для $\mathrm{CO}_{2}$ может существенно превышать таковое для $\mathrm{CH}_{4}-$ не говоря уже о том, что процессы дыхания и метанокисления действительно могут иметь разные величины $Q_{10}$. Обсудим этот вопрос несколько подробнее. 
Таблица 5. Поглощение метана почвами разных структурных классов в различных биомах ${ }^{9)}$, согласно [Dutaur and Verchot, 2007].

\begin{tabular}{|c|c|c|c|c|c|c|c|}
\hline \multirow{2}{*}{$\begin{array}{l}\text { Климати- } \\
\text { ческий пояс }\end{array}$} & \multirow{2}{*}{\begin{tabular}{|c|}
$\begin{array}{c}\text { Эко- } \\
\text { системы }\end{array}$ \\
\end{tabular}} & \multirow{2}{*}{$\begin{array}{c}\text { Структурный } \\
\text { класс }\end{array}$} & \multicolumn{2}{|c|}{ Площадь $\left(\kappa м^{2}\right)$} & \multirow{2}{*}{$\begin{array}{c}\text { Сделано } \\
\text { измерений }\end{array}$} & \multicolumn{2}{|c|}{ Поглощение $\mathrm{CH}_{4}($ среднее \pm СКО) } \\
\hline & & & в мире & в $\boldsymbol{P} \Phi^{I)}$ & & $\Pi \Pi \Pi\left(m \cdot \kappa M^{-2} \cdot 20 \partial^{-1}\right)$ & Поток в РФ \\
\hline \multirow{12}{*}{$\begin{array}{c}\text { Бореаль- } \\
\text { ный }\end{array}$} & \multirow{6}{*}{ Лесные } & Organic & 1760000 & 234342 & 28 & $0.36 \pm 0.32$ & $0.084 \pm 0.074$ \\
\hline & & Coarse & 3060000 & 356708 & 6 & $0.32 \pm 0.28$ & $0.114 \pm 0.098$ \\
\hline & & Coarse-Medium & н.д. ${ }^{2)}$ & 199377 & н.д. ${ }^{2)}$ & $0.19 \pm 0.17^{4,5)}$ & $0.037 \pm 0.033$ \\
\hline & & Medium & 11180000 & 4063775 & 14 & $0.05 \pm 0.04$ & $0.203 \pm 0.182$ \\
\hline & & Medium-Fine & н.д. ${ }^{2}$ & 333498 & н.д. ${ }^{2}$ & $0.13 \pm 0.12$ & $0.042 \pm 0.039$ \\
\hline & & Fine & 870000 & 113127 & 1 & $0.2 \pm 0.18^{5)}$ & $0.023 \pm 0.020$ \\
\hline & \multirow{6}{*}{$\begin{array}{l}\text { Без- } \\
\text { лесные }\end{array}$} & Organic & 50000 & 296336 & 8 & $0.17 \pm 0.28$ & $0.050 \pm 0.082$ \\
\hline & & Coarse & 1080000 & 559075 & 3 & $0.10 \pm 0.03$ & $0.056 \pm 0.018$ \\
\hline & & Coarse-Medium & н.д. ${ }^{2)}$ & 227660 & Н.д. ${ }^{2)}$ & $0.10 \pm 0.09^{4,5)}$ & $0.023 \pm 0.022$ \\
\hline & & Medium & 2770000 & 6192580 & 3 & $0.10 \pm 0.04$ & $0.619 \pm 0.277$ \\
\hline & & Medium-Fine & н.д. ${ }^{2}$ & 84424 & н.д. ${ }^{2)}$ & $0.15 \pm 0.14^{4,5)}$ & $0.013 \pm 0.012$ \\
\hline & & Fine & 60000 & 513399 & 0 & $0.2 \pm 0.18^{5,6)}$ & $0.103 \pm 0.091$ \\
\hline \multirow{12}{*}{$\begin{array}{c}\text { Умерен- } \\
\text { ный }\end{array}$} & \multirow{6}{*}{ Лесные } & Organic & 80000 & 10249 & 7 & $0.46 \pm 0.32$ & $0.005 \pm 0.003$ \\
\hline & & Coarse & 1000000 & 82821 & 30 & $0.75 \pm 0.58$ & $0.062 \pm 0.048$ \\
\hline & & Coarse-Medium & н.д. ${ }^{2)}$ & 11513 & н.д. ${ }^{2)}$ & $0.66 \pm 0.56^{4,5)}$ & $0.008 \pm 0.006$ \\
\hline & & Medium & 3600000 & 794854 & 43 & $0.56 \pm 0.61$ & $0.445 \pm 0.484$ \\
\hline & & Medium-Fine & н.д. ${ }^{2}$ & 17536 & н.д. ${ }^{2)}$ & $0.40 \pm 0.34^{4,5)}$ & $0.007 \pm 0.006$ \\
\hline & & Fine & 1140000 & 28748 & 12 & $0.23 \pm 0.12$ & $0.007 \pm 0.004$ \\
\hline & \multirow{6}{*}{$\begin{array}{l}\text { Без- } \\
\text { лесные }\end{array}$} & Organic & 100000 & 22880 & 9 & $0.14 \pm 0.12$ & $0.003 \pm 0.003$ \\
\hline & & Coarse & 10350000 & 94098 & 18 & $0.17 \pm 0.13$ & $0.016 \pm 0.012$ \\
\hline & & Coarse-Medium & н.Д. ${ }^{2)}$ & 5524 & н.д. ${ }^{2)}$ & $0.17 \pm 0.15^{4,5)}$ & $0.001 \pm 0.001$ \\
\hline & & Medium & 28240000 & 1486639 & 36 & $0.17 \pm 0.24$ & $0.253 \pm 0.215$ \\
\hline & & Medium-Fine & н.д. ${ }^{2)}$ & 111680 & н.д. ${ }^{2)}$ & $0.15 \pm 0.13^{4,5)}$ & $0.016 \pm 0.015$ \\
\hline & & Fine & 5560000 & 202792 & 6 & $0.12 \pm 0.21$ & $0.024 \pm 0.043$ \\
\hline \multirow{8}{*}{ Тропический } & \multirow{4}{*}{ Лесные } & Organic & 120000 & 0 & 2 & 0.36 & $0.000 \pm 0.000$ \\
\hline & & Coarse & 2430000 & 0 & 16 & $0.43 \pm 0.26$ & $0.000 \pm 0.000$ \\
\hline & & Medium & 9320000 & 0 & 19 & $0.38 \pm 0.19$ & $0.000 \pm 0.000$ \\
\hline & & Fine & 7450000 & 0 & 21 & $0.21 \pm 0.12$ & $0.000 \pm 0.000$ \\
\hline & \multirow{4}{*}{$\begin{array}{l}\text { Без- } \\
\text { лесные }\end{array}$} & Organic & 30000 & 0 & 0 & н.Д. & $0.000 \pm 0.000$ \\
\hline & & Coarse & 4810000 & 0 & 12 & $0.09 \pm 0.12$ & $0.000 \pm 0.000$ \\
\hline & & Medium & 8830000 & 0 & 6 & $0.23 \pm 0.08$ & $0.000 \pm 0.000$ \\
\hline & & Fine & 4310000 & 0 & 6 & $0.15 \pm 0.10$ & $0.000 \pm 0.000$ \\
\hline & & & & & & ВСЕГО: & $2.2 \pm 0.7$ \\
\hline
\end{tabular}

Примечания:

1)Результаты наших расчетов.

${ }^{2)}$ Нет данных (видимо, Dutaur and Verchot [2007] относили почвы промежуточного класса к каким-либо основным классам).

${ }^{3)}$ См. Примечание 6 к табл. 2.

4) B [Dutaur and Verchot, 2007] данный промежуточный класс отсутствовал, поэтому мы следовали правилу, сформулированному в [Dörr et al., 1993]: если удельный поток для смешанных структурных классов не известен, то он принимается равным среднему арифметическому удельных потоков для основных классов.

${ }^{5)}$ Нетрудно заметить, что из исходных данных [Dutaur and Verchot, 2007] следует приближенная линейная связь между значением удельного потока $(x)$ и его средним квадратическим отклонением $(\mathrm{CKO}): \mathrm{CKO}=0.8312 \cdot x+0.0116\left(\mathrm{R}^{2}=0.8507\right)$, поэтому при отсутствии экспериментальных данных для СКО мы его рассчитывали по значению удельного потока при помощи вышеуказанной зависимости.

${ }^{6)}$ В [Dutaur and Verchot, 2007] значение удельного потока отсутствовало, поэтому мы приняли его равным таковому для класса «Fine в Лесных экосистемах Бореального пояса».

${ }^{9)}$ См. Примечание 9 к таблице 4.

\section{Как могут возникнуть завышенные значения $Q_{10}$ ?}

Из химической кинетики известно, что при повышении температуры на 10 градусов скорость реакции возрастает в $Q_{10}=3 \pm 1$ раза [Панченков и Лебедев, 1985, с. 37]. Однако в литературе часто встречаются значительно более высокие значения $Q_{10}$, наблюдавшиеся при изучении биологических процессов (многочисленные литературные ссылки на самые разные - как высокие, так и низкие значения $Q_{10}$ при метаногенезе приведены в [Глаголев, 2004], повышенные величины $Q_{10}$ для дыхания некоторых почв наблюдал А.В. Наумов [2009, с. 55-57, 62, 127]). Для объяснения аномально высоких значений $Q_{10}$ было предложено несколько гипотез. Здесь мы кратко упомянем три из них.

В [Глаголев, 2004] показано, что $\boldsymbol{\kappa}$ завышенным кажущимся значениям $Q_{10}$ может привести неоптимальное размещение температурных датчиков в профиле почвы, однако эта гипотеза не 
сможет объяснить высокие $Q_{10}$, если они будут наблюдаться в небольших образцах в лабораторных условиях или, тем более, в культурах микроорганизмов с полным перемешиванием.

А.В. Наумов $\left[2009\right.$, с. 55] предполагает, что высокие величины $Q_{10}$ связаны с температурной стимуляцией роста биомассы различных компонентов биоценоза. Само понятие коэффициента $Q_{10}$ вводилось в химической кинетике в предположении, что скорости измеряются для одних и тех жее количеств реагентов при разных температурах. В биологической кинетике это условие на практике иногда не соблюдается - из-за роста биомассы получается, что за время, прошедшее от измерения при низкой температуре до измерения при высокой температуре количество биомассы увеличилось, т.е. когда проводилось измерение при высокой температуре больше было и количество «реагента».

А.В. Смагин с соавт. [2010], в отличие от А.В. Наумова, объясняют высокие кажущиеся $Q_{10}$ не столько биологическими, сколько физико-химическими процессами: «Дыхание есть результат комбинации процессов выделения $\mathrm{CO}_{2}$ микроорганизмами и корнями, его диффузионного и конвективного транспорта к границам почвы, (био)химических реакций (осаждение/растворение карбонатов и гидрокарбонатов, иные реакции), физико-химических межфазных взаимодействий (растворения/дегазации, адсорбции/десорбции). Все эти процессы нелинейным образом зависят от температуры и влажности. Отсюда получаются абсурдные с биохимической точки зрения величины $Q_{10}$ в 7-12 единиц и более, вместо 2-3; ведь сама модель Вант-Гоффа разработана для реакций, а ею аппроксимируется сложный процесс, содержащий наряду с реакциями транспорт, физикохимические межфазные взаимодействия». Конкретизируя эти общие положения о сложных физикохимических межфазных взаимодействиях, можно сказать, что высокие значения $Q_{10}$ могут быть вызваны не биологическими процессами, а, например, дегазацией (при более высокой температуре) раствора, содержащего тот $\mathrm{CO}_{2}$, который попал туда ранее (когда измерения велись при меньшей температуре).

\section{Падение корреляции потока с факторами среды при расширении географии исследований}

Однако, если зависимость поглощения $\mathrm{CH}_{4}$ от средней температуры почвы все-таки существует, то возникает вопрос: почему соответствующую корреляцию не обнаружили Dutaur and Verchot [2007]? Один из ответов можно дать на основании идеи, сформулированной в [Глаголев с соавт., 2007], где показано, что с увеличением области исследования, с вовлечением в измерения все большего числа новых объектов, коэффициент корреляции между удельным потоком метана (УП) и конкретным фактором среды (ФС) будет уменьшаться при некотором часто применяемом типе зависимости УП от ФС. Рассмотрим это на конкретном примере.

По закону Фика абсолютное значение потока метана в почву составит $J=D \cdot G$, где $D$ коэффициент диффузии верхнего слоя почвы, а $G$ - абсолютное значение градиента концентрации метана в верхнем слое почвы [Potter et al., 1996; Ridgwell et al., 1999]. Пусть мы изучаем зависимость поглощения метана от температуры $\left(T,{ }^{\circ} \mathrm{C}\right)$. Вообще говоря, эта зависимость будет определяться произведением температурных зависимостей $D(T)$ и $G(T)$. Однако сейчас для простоты мы будем считать $G(T)$ весьма слабо зависящим от температуры - настолько слабо, что этой зависимостью можно пренебречь (как будет видно из дальнейшего, на суть дела это предположение никак не влияет).

С хорошей степенью приближения можно принять, что $D(T) \sim 0.9734+0.0055 \cdot T$ [Potter et al., 1996$]$. Пусть изучается некоторый биогеоценоз, в почве которого содержится относительно мало влаги (но, тем не менее, вполне достаточно, чтобы активно шло потребление метана). Пока исследования ведутся в рамках этого биогеоценоза, $J(T) \sim 0.9734+0.0055 \cdot T$ и коэффициент корреляции может быть довольно высок. Но вовлечем теперь в исследования еще один биогеоценоз, почвы которого, в отличие от первого, насыщены влагой настолько, что метанокисление почти не идет (или идет, но уравновешивается метанобразованием). Тогда будем иметь $G \approx 0$ и, несмотря на остающуюся зависимость $D(T)$, измерения дадут здесь $J \approx 0$, т.е. зависимости поглощения от температуры во втором биогеоценозе выявлено не будет. Понятно, что объединение экспериментальных данных, полученных в первом и втором биогеоценозах, снизит высокую корреляцию между поглощением метана и температурой, которая наблюдалась тогда, когда имелся массив данных, полученных лишь для первого биогеоценоза.

\section{ИСПОЛЬЗОВАНИЕ РАЗЛИЧНЫХ ИНВЕНТАРИЗАЦИЙ ДЛЯ РЕГИОНАЛЬНОЙ ОЦЕНКИ ПОГЛОЩЕНИЯ $\mathrm{CH}_{4}$}

\section{Подзона средней тайги Западной Сибири}

Согласно карте Ильиной с соавт. [1976] с границами подзон согласно Гвоздецкому и др. [1973], в средней тайге Западной Сибири бореальные леса и мезофильные травяные экосистемы (луга) занимают, 


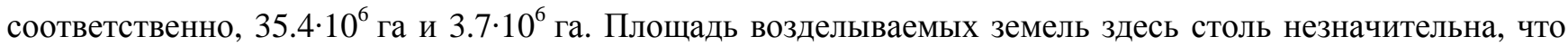
на указанной карте она совершенно не отражена и для наших приближенных расчетов вполне может быть принята нулевой. Таким образом, согласно [Born et al., 1990] - см. табл. 1 - поглощение метана в средней тайге Западной Сибири должно составлять

$\left(35.4 \cdot 10^{10} \mathrm{M}^{2}\right) \cdot\left(0.09 \div 1.3 \Gamma^{\cdot} \mathrm{M}^{-2} /\right.$ год $)+\left(3.7 \cdot 10^{10} \mathrm{M}^{2}\right) \cdot\left(0.002 \div 0.2 \Gamma^{\cdot} \mathrm{M}^{-2} /\right.$ год $)=(3.19 \div 46.8) \cdot 10^{10}$ г/год $\approx 0.03 \div 0.47 \mathrm{Mт} /$ год.

Средняя оценка (середина полученного интервала) $q_{\mathrm{B}}=0.25 \mathrm{Mт} /$ год.

Согласно [Dutaur and Verchot, 2007] - см. табл. 4 - поглощение метана в средней тайге Западной Сибири должно составлять

$$
q_{\mathrm{D}}=\left(35.4 \cdot 10^{6} \text { га) }\right) \cdot\left(2.64 \text { кг } \cdot \mathrm{ra}^{-1} \cdot \text { год }^{-1}\right)+\left(3.7 \cdot 10^{6} \text { га) } \cdot\left(2.32 \kappa \cdot \mathrm{ra}^{-1} \cdot \text { год }^{-1}\right)=1.02 \cdot 10^{8} \text { кг } \cdot \text { год }^{-1}=0.102 \mathrm{Mт} \cdot \text { год }^{-1} .\right.
$$

Учитывая то, что в табл. 4 приведены не только величины средних годовых поглощений $\mathrm{CH}_{4}$ в различных экосистемах, но и их дисперсии, по инвентаризации [Dutaur and Verchot, 2007] также можно оценить некоторый интервал регионального поглощения метана. Однако сопоставить его с интервалом, полученным по инвентаризации [Born et al., 1990] затруднительно, поскольку в последнем случае авторы не указывают - какую характеристику разброса они используют. Тем не менее, если в инвентаризации [Dutaur and Verchot, 2007] использовать одно стандартное отклонение, то мы получим интервал практически от нуля до

$$
35.4 \cdot 10^{6} \cdot(2.64+2.84)+3.7 \cdot 10^{6} \cdot(2.32+1.71)=2.09 \cdot 10^{8}{\text { кг } \cdot \text { год }^{-1}=0.209 \text { Мт } \cdot \text { год }}^{-1} .
$$

Таким образом, по порядку величин оценки годового поглощения метана почвами средне-таежной подзоны Западной Сибири, полученные на основе [Born et al., 1990] и [Dutaur and Verchot, 2007], совпадают. Усредненная оценка (арифметическое среднее $q_{\mathrm{B}}$ и $q_{\mathrm{D}}$ ) составляет $0.176 \mathrm{Mт} \cdot{ }^{-}$со $^{-1}$. Для сравнения укажем, что, согласно инвентаризации Bc8 [Glagolev et al., 2011; Sabrekov et al., 2011], болота данной подзоны этого региона выбрасывают в атмосферу $0.707 \mathrm{Mт}^{-}$год $^{-1}$. Иначе говоря, поглощение метана почвами средне-таежной подзоны Западной Сибири составляет приблизительно $25 \%$ от эмиссии этого газа местными болотами.

\section{Поглощение метана почвами всей территории России}

Теперь рассмотрим использование описанных выше различных вариантов МеПИ для расчета поглощения метана почвами всей России.

Все расчеты (растровая математика, площади) выполнялись нами в ГИС GRASS 6.4 [GRASS..., 2011]. Все площадные расчеты произведены в конической равновеликой проекции Альберса для территории РФ (центральный меридиан 105, 1-я и 2-я стандартные параллели, соответственно 52, и 64, сфероид Красовского). Для ограничения вычислений территорией Российской Федерации, были использованы границы субъектов РФ (согласно Росреестру) по состоянию на 2010 год, оцифрованные в ходе коллективного проекта сообщества ГИС-Лаб [Свободные..., 2010]. Матрица текстуры почв мира с разрешением в 1 градус была взята из базы данных почвенных типов NASA [Zobler, 1986].

Результаты расчетов годового поглощения метана почвенным покровом России, полученные на основании отнесения почв к тому или иному классу структуры (т.е. расчетов по методу [Dörr et al., 1993] и одному из методов [Dutaur and Verchot, 2007]), приведены в табл. 6. Бросается в глаза чрезвычайно большая ( $\approx 330 \% ! ! !)$ погрешность оценки, полученной по [Dutaur and Verchot, 2007]. Однако это вполне естественно - ведь этот расчет основан на табл. 2, а в ней мы видим, что (по данным указанных авторов) средние квадратические отклонения (СКО) во всех случаях в 2-4 раза превышают соответствующие средние значения удельных потоков в почвах различной структуры. Это резко отличается от данных [Dörr et al., 1993], где СКО составляют лишь 60-90\% величин удельных потоков. Можно подумать, что оценка Dörr et al. [1993] точнее. Однако напомним, что эти авторы экспериментально исследовали почти одни только почвы под лесом, а спектр почв, исследованных в [Dutaur and Verchot, 2007] шире. Таким образом, возможно, данный результат говорит о том, что нельзя ограничиваться лишь структурой почвы при вычислении поглощения ею метана. К этому же выводу приводит и формальный аппарат математической статистики - см. Приложение.

\footnotetext{
${ }^{8}$ При этом, за неимением лучшего, мы предполагаем, что луга бореального пояса (которых в табл. 1 нет) поглощают метан так же, как и луга умеренного пояса (имеющиеся в табл. 1).
} 


\begin{tabular}{|c|c|c|c|}
\hline \multirow{2}{*}{$\begin{array}{c}\text { Структурный } \\
\text { класс }\end{array}$} & \multirow{2}{*}{ 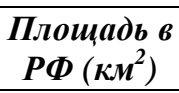 } & \multicolumn{2}{|c|}{ Поток") в РФ (Мт/год), рассчитанный (см. табл. 2) по } \\
\hline & & [Dörr et al., 1993] & [Dutaur and Verchot, 2007] \\
\hline Coarse & 1202570 & $0.625 \pm 0.469$ & $0.505 \pm 1.744$ \\
\hline Medium & 12832193 & $2.053 \pm 1.797$ & $4.235 \pm 17.195$ \\
\hline Fine & 878749 & $0.062 \pm 0.035$ & $0.176 \pm 0.369$ \\
\hline Coarse-Medium & 490533 & $0.167 \pm 0.132$ & $0.186 \pm 0.687$ \\
\hline Medium-Fine & 552987 & $0.066 \pm 0.050$ & $0.149 \pm 0.487$ \\
\hline ВСЕГО: & & $3.0 \pm 1.9$ & $5.3 \pm 17.3$ \\
\hline
\end{tabular}

Таблица 6.

Распространенность в России почв разных структурных классов, способных к поглощению $\mathrm{CH}_{4}$.

*) Примечание: характеристики погрешности (в записи «среднее \pm погрешность») см. в табл. 2 - Примечания 6 и 7.

Для экстраполяции данных измерений из [Born et al., 1990] (табл. 1) и [Dutaur and Verchot, 2007] (табл. 4) поглощения метана почвами различных биомов, мы использовали продукт MODIS 3-го уровня обработки «MCD12Q1» [NASA...], представляющий набор классифицированных растров глобального охвата, имеющих 500-м пространственное разрешение. Продукт включает набор из 5 различных классификационных схем растительного покрова, а также служебные слои оценки качества классификации растров. Нами была использована наиболее дробная классификационная схема ландшафтного покрова Международной геосферно-биосферной программы (IGBP) [Belward et al, 1999], включающая 16 классов (1-й слой продукта MCD12Q1) - табл. 7.

Таблица 7. Схема классификации ландшафтного покрова по IGBP продукта MCD12Q1 MODIS и результаты визуальной валидации исходных классов по снимкам Landsat на территорию РФ.

\begin{tabular}{|l|l|l|}
\hline ID & MODIS MCD12Q1 (классы по IGBP) & Соответствующие ландиафты на территории РФ \\
\hline 0 & Water & Водные объекты \\
\hline 1 & Evergreen Needleleaf forest & Темнохвойные леса \\
\hline 2 & Evergreen Broadleaf fores & Нет в РФ \\
\hline 3 & Deciduous Needleleaf forest & Лиственничные леса Средней и Восточной Сибири \\
\hline 4 & Deciduous Broadleaf forest & Дальневосточные широколиственные леса \\
\hline 5 & Mixed forest & Смешанные леса \\
\hline 6 & Closed shrublands & В основном лесотундра \\
\hline 7 & Open shrublands & Различные типы тундр \\
\hline 8 & Woody savannas & В основном лесотундра \\
\hline 9 & Savannas & В РФ не представлен, отдельные шумы в зоне Лесотундры \\
\hline 10 & Grasslands & Травянистые экосистемы, включая травянистые тундры, \\
& & степи и полупустыни \\
\hline 11 & Permanent wetlands & Различные типы болот \\
\hline 12 & Croplands & Возделываемые земли \\
\hline 13 & Urban and built-up & Застройка \\
\hline 14 & Cropland/Natural vegetation mosaic & Комплекс пашен и естественной растительности \\
\hline 15 & Snow and ice & Снег и лед \\
\hline 16 & Barren or sparsely vegetated & Пустыни и разреженная растительность \\
\hline
\end{tabular}

После визуальной оценки классифицированного по схеме IGBP растра и сравнения его с космической съемкой Landsat исходный продукт «MCD12Q1» был доработан нами в следующих направлениях (непосредственно для нужд инвентаризации метанокисления почвами):

- Классы 1, 2, 3, 4 и 5 объединили в класс лесов, разбив его на 2 подкласса: леса бореального пояса и леса умеренного пояса. Для разбиения была использована карта глобального экорегионального зонирования Бэйли на уровне доменов: Polar domain - бореальные леса, Humid Temperate Domain леса умеренного пояса [Bailey and Hogg, 1986] (электронный вариант - см. [Дубинин, 2006]).

- Классы 6, 8, 9 объединили в класс лесотундры.

- Класс 7, включавший различные типы тундр, дополнили значениями из класса 10 (травянистые экосистемы), приходящимися на Polar Domain Бэйли. Таким образом, класс тундр стал включать не только кустарничковые, но и травяные тундры.

- Из класса 10 (травянистые экосистемы) выделили класс полупустынь, использовав границы классификационной единицы пустынь умеренного пояса Бэйли [Bailey and Hogg, 1986] и добавили класс 16 (пустыни).

- Классы 12 и 14 объединили в класс возделываемых земель. 
- Классы 0, 11, 13 и 15 (вода, болота, городская застройка, лед) объединили в класс территорий, не поглощающих метан.

Модифицированные классы представлены в табл. 8. Именно такие классы были использованы для расчета почвенного поглощения метана почвами разных биомов (т.е. по Born et al. [1990] - см. табл. 1, и по одному из методов Dutaur and Verchot [2007] - тому, который представлен в табл. 4).

\begin{tabular}{|c|l|l|}
\hline ID & \multicolumn{1}{|c|}{ MCD12Q1 Landcover } & \multicolumn{1}{c|}{ ID (IGBP) } \\
\hline 1 & Boreal forest (леса бореального пояса) & $(1,2,3,4,5)$ boreal \\
\hline 2 & Temperate forest (леса умеренного пояса) & $(1,2,3,4,5)$ temperate \\
\hline 3 & Forest-tundra (лесотундра) & $6,8,9$ \\
\hline 4 & Tundra (тундра) & $7+10^{*}$ \\
\hline 5 & Steppe (степь) & 10 \\
\hline 6 & Croplands (возделываемые земли) & 12,14 \\
\hline 7 & Semidesert (полупустыни) & $16+10^{*}$ \\
\hline 8 & No absorbtion (болота) & $0,11,13,15$ \\
\hline
\end{tabular}

Таблица 8.

Классы модифицированной классификации IGBP продукта MODIS MCD12Q1.

Для расчетов поглощения почвами разной структуры в разных биомах (т.е. по другому методу Dutaur and Verchot [2007] - тому, который представлен в табл. 5) был использован модифицированный нами тематический растр (классы перечислены в табл. 8), который претерпел дальнейшую модификацию: лесные классы 1 и 2 были объединены в класс «лесные экосистемы», ландшафты, не поглощающие метан, были оставлены в соответствующем классе, все остальные были помещены в класс «безлесные экосистемы». Полученный растр был скомбинирован со слоем доменов экорегионального зонирования Бэйли [Bailey and Hogg, 1986] и, таким образом, был получен слой, включающий 5 классов: 1) бореальные лесные экосистемы, 2) бореальные безлесные экосистемы, 3) умеренные лесные экосистемы, 4) умеренные безлесные экосистемы, 5) экосистемы, не поглощающие метан. Далее, этот промежуточный слой был скомбинирован со слоем структурных классов Зоблера [Zobler, 1986] и каждый класс промежуточного слоя был разбит еще на 5 структурных классов почв. В итоге для почв России было получено 25 классов 9

Таблица 9. Поглощение метана почвами России, вычисленное по методам разных авторов.

\begin{tabular}{|c|c|c|}
\hline \multicolumn{2}{|r|}{ Методика } & \multirow{2}{*}{$\begin{array}{c}\text { Поток*), } \\
\text { Мm/год }\end{array}$} \\
\hline Aвторы & Краткое описание & \\
\hline Born et al., 1990 & Каждому биому приписывается характерная ППП $\mathrm{CH}_{4}$ - см. табл. 1. & $9.6 \pm 5.4$ \\
\hline Dörr et al., 1993 & Каждому структурному классу почв приписывается характерная ППП СН 4 - см. табл. 6. & $3.0 \pm 1.9$ \\
\hline Zelenev, 1996 & $\begin{array}{l}\text { Каждому типу автоморфных почв приписывается характерная ППП } \mathrm{CH}_{4} \text {. В качестве оценки } \\
\text { потока мы дали середину интервала неопределенности } \pm \text { размах. Но из-за несимметричности } \\
\text { распределения, в [Zelenev, 1996] наиболее вероятное значение оценивается величиной } 0.17 \text {, а не } \\
0.27 \text { Мт/год. }\end{array}$ & $0.27 \pm 0.16$ \\
\hline \multirow{3}{*}{$\begin{array}{l}\text { Dutaur and } \\
\text { Verchot, } 2007\end{array}$} & Каждому структурному классу почв приписывается характерная ППП СН 4 - см. табл. 6. & $5.3 \pm 17.3$ \\
\hline & Каждому биому приписывается характерная ППП $\mathrm{CH}_{4}-$ см. табл. 4. & $3.6 \pm 2.5$ \\
\hline & $\begin{array}{l}\text { Каждому структурному классу почв в каждом биоме приписывается характерная ППП } \mathrm{CH}_{4}- \\
\text { см. табл. } 5 .\end{array}$ & $2.2 \pm 0.7$ \\
\hline
\end{tabular}

*) Примечание: характеристики погрешности (в записи «среднее \pm погрешность») см. в соответствующих табл.

Для удобства сравнения мы свели все результаты расчета годового поглощения $\mathrm{CH}_{4}$ почвами России в табл. 9. Из нее видно, что (за исключением оценки В.В. Зеленева) все оценки находятся в довольно близком соответствии друг другу, если учитывать их погрешности. Действительно, минимальная оценка Born et al. [1990] составляет 4.2 Мт/год, перекрываясь, таким образом, с оценкой Dörr et al. [1993] и двумя оценками Dutaur and Verchot [2007]. Максимальное значение третьей оценки Dutaur and Verchot [2007] несколько ниже (оно составляет 2.9 Мт/год). Следовательно, в качестве значения, наиболее близкого ко всем оценкам (кроме оценки В.В. Зеленева), можно принять 3.6 Мт/год. Относительно же оценки из [Zelenev, 1996] следует сказать, что в те годы, когда она была получена, на территории РФ еще не было развернуто систематического измерения ППП $\mathrm{CH}_{4}$. В результате, в его работе $40.3 \%$ площади РФ вообще оказалось не обеспечено экспериментальной информацией ${ }^{10}$ (т.е. для

\footnotetext{
${ }^{9}$ В табл. 5 не внесен класс «Не поглощающие $\mathrm{CH}_{4}$ (вода, лед, застройка, болота)».

${ }^{10}$ Чтобы читатель мог себе зримо представить, какая часть РФ не была изучена В.В. Зеленевым, заметим, что упомянутые $40.3 \%$ площади - это несколько больше, чем Европейская часть РФ и Западная Сибирь вместе взятые.
} 
распространенных там типов почв не было известно ни одного измерения ППП $\left.\mathrm{CH}_{4}\right)$ : $38.4 \%$ на территории без многолетне-мерзлых пород и $41.7 \%$ на территории распространения вечной мерзлоты.

\section{БЛАГОДАРНОСТЬ}

Авторы выражают благодарность Европейскому Союзу за поддержку данной работы по проекту FP7-ENVIRONMENT PAGE21, контракт №GA282700.

\section{ЛИТЕРАТУРА}

Бейли Н. 1970. Математика в биологии и медицине. М.: Мир.

Блохин А.В. 2002. Теория эксперимента. Курс лекций. Минск: БГУ. Ч. 1. 68 с.

Гвоздецкий Н.А., Криволуцкий А.Е., Макунина А.А. 1973. Схема физико-географического районирования Тюменской области // Физико-географическое районирование Тюменской области. М.: МГУ. С. 9-28.

Глаголев М.В. 2004. Элементы количественной теории процессов образования и потребления метана в почве // Болота и биосфера: Сборник материалов Третьей Научной Школы (13-16 сентября 2004 г.). Томск: Изд-во ЦНТИ. С. 39-52.

Глаголев М.В. 2006. Математическое моделирование метанокисления в почве // Труды Института микробиологии имени С.Н. Виноградского РАН. Вып. ХІІІ: К 100-летию открытия метанотрофии / Под. ред. В.Ф. Гальченко. М.: Наука. С. $315-341$.

Глаголев М.В. 2007. Оценка эмиссии метана заболоченными территориями Западной Сибири // Болота и биосфера: Сборник материалов Шестой Научной Школы (10-14 сентября 2007 г.). Томск: Изд-во ФГУ «Томский ЦНТИ». С. 33-41.

Глаголев М.В. 2010. К методу «обратной задачи» для определения поверхностной плотности потока газа из почвы // Динамика окружающей среды и глобальные изменения климата. T. 1. № 1. С. 17-36. Также доступна по URL (дата обращения: 30.07.2010): http://www.ugrasu.ru/uploads/files/Glagolev\%20(1).pdf.

Глаголев М.В., Головацкая Е.А., Шнырев Н.А. 2007. Эмиссия парниковых газов на территории Западной Сибири // Сибирский экологический журнал. Т. 14. № 2. С. 197-210.

Глаголев М.В., Смагин А.В. 2005. Приложения MATLAB для численных задач биологии, экологии и почвоведения. М.:

МГУ им. М.В. Ломоносова. 200 с.

Дмитриев Е.А. 1995. Математическая статистика в почвоведении. М.: Изд-во МГУ. 320 с.

Дубинин М.Ю. 2006. Глобальное экорегиональное зонирование Бэйли. GIS-Lab.info. Данные доступны по URL (дата обращения: 19.05.2011): http://gis-lab.info/qa/bailey.html

Елецкий А.В. 1991. Диффузия // Физические величины. Справочник / Под ред. И.С. Григорьева и Е.3. Мейлихова. М.: Энергоатомиздат. с. 375-390.

Заварзин Г.А. 1995. Микробный цикл метана в холодных условиях // Природа. № 6. С. 3-14.

Ильина И.С., Лапшина Е.И., Махно В.Д., Романова Е.А. 1976. Растительность Западно-Сибирской равнины (карта). М 1: 1500000. ГУГК. 4 л.

Кондратьев К.Я., Крапивин В.Ф., Савиных В.П. 2003. Перспективы развития цивилизации: многомерный анализ. М.: Логос. 576 с.

Королюк В.С., Портенко Н.И., Скороход А.В., Турбин А.Ф. 1985. Справочник по теории вероятностей и математической статистике. М.: Наука. 640 с.

Лозе Ж., Матье К. 1998. Толковый словарь по почвоведению. М.: Мир. 398 с.

Наумов А.В. 2009. Дыхание почвы: составляющие, экологические функции, географические закономерности. Новосибирск: Изд-во СО РАН. 208 с.

Панченков Г., Лебедев В. 1985. Химическая кинетика и катализ. М.: Химия. 592 с.

Румшиский Л.3. 1971. Математическая обработка результатов эксперимента. М.: Наука. 192 с.

Свободные данные по границам субъектов РФ. 2010. Росреестр, GIS-Lab.info. URL (дата обращения: 19.05.2011): http://gis-lab.info/qa/rusbounds-rosreestr.html

Смагин А.В., Садовникова Н.Б., Щерба Т.Э., Шнырев Н.А. 2010. Абиотические факторы дыхания почв // Экологический вестник Северного Кавказа. Т. 6. № 1. С. 5-14.

Филиппов Л.П. 1986. Явления переноса. М.: Изд-во МГУ. 120 с.

Хайди Г.М. 1976. Процессы удаления газообразных и взвешенных загрязнений из атмосферы // Химия нижней атмосферы / Под ред. Расул С. М.: Мир. С. 155-222.

Чернавина И.А., Потапов Н.Г., Косулина Л.Г., Кренделева Т.Е. 1978. Большой практикум по физиологии растений. М.: Высш. школа. 408 с. 195-202.

Bailey R.G., Hogg H.C. 1986. A world ecoregions map for resource reporting // Environmental Conservation. V. 13. No. 3. P.

Bartlett K.B., Sachse G.W., Slate T., Harward C., Blake D.R. 2003. Large-scale distribution of $\mathrm{CH}_{4}$ in the western North Pacific: Sources and transport from the Asian continent // J. Geophys. Res. V. 108. No. D20. 8807. doi:10.1029/2002JD003076.

Belward A.S., Estes J.E., Kline K.D. 1999. The IGBP-DIS Global 1-km Land-Cover Data Set DISCover: A Project Overview // Photogram. Eng. Remote Sens. V. 65. P. 1013-1020.

Bender M., Conrad R. 1993. Kinetics of methane oxidation in oxic soils // Chemosphere. V. 26. No. 1-4. P. 686-696.

Bergamaschi P., Frankenberg C., Meirink J.F., Krol M., Dentener F., Wagner T., Platt U., Kaplan J.O., Körner S., Heimann M., Dlugokencky E.J., Goede A. 2007. Satellite chartography of atmospheric methane from SCIAMACHY on board ENVISAT: 2. Evaluation based on inverse model simulations // Journal of Geophysical Research. V. 112. D02304. DOI:10.1029/2006D007268.

Boeckx P., van Cleemput O. 1996. Methane Oxidation in a Neutral Landfill Cover Soil: Influence of Moisture Content, Temperature, and Nitrogen-Turnover // Journal of Environmental Quality. V. 25. P. 178-183.

Boeckx P., van Cleemput O., Villaralvo I. 1996. Methane emission from a landfill and the methane oxidising capacity of its covering soils // Soil Biology and Biochemistry. V. 28. No. 10/11. P. 1397-1405.

Börjesson G. 2001. Inhibition of methane oxidation by volatile sulfur compounds $\left(\mathrm{CH}_{3} \mathrm{SH}\right.$ and $\left.\mathrm{CS}_{2}\right)$ in landfill cover soils // Waste Management \& Research. V. 19. P. 314-319.

Born M., Dorr H., Levin I. 1990. Methane consumption in aerated soils of the temperate zone // Tellus B. V. 42. P. 2-8. 
Cai Z., Yan X. 1999. Kinetic model for methane oxidation by paddy soil as affected by temperature, moisture and N addition // Soil Biology and Biochemistry. V. 31. P. 715-725.

Chan A.S.K., Parkin T.B. 2000. Evaluation of potential inhibitors of methanogenesis and methane oxidation in a landfill cover soil // Soil Biology and Biochemistry. V. 32. P. 1581-1590.

Chiemchaisri W., Visvanathan C., Wu J.S. 2001. Effects of Trace Volatile Organic Compounds on Methane Oxidation // Brazilian Archives of Biology and Technology. V. 44. No. 2. P. 135-140.

Christophersen M., Linderød L., Jensen P.E., Kjeldsen P. 2000. Methane Oxidation at Low Temperatures in Soil Exposed to

Landfill Gas // Journal of Environmental Quality. V. 29. P. 1989-1997.

Curry C.L. 2007. Modeling the soil consumption of atmospheric methane at the global scale // Global Biogeochemical Cycles.

V. 21. GB4012. DOI:10.1029/2006GB002818.

Curry C.L. 2009. The consumption of atmospheric methane by soil in a simulated future climate // Biogeosciences. V.6.

Issue 11. P. 2355-2367. URL: www.biogeosciences.net/6/2355/2009/ (дата обращения: 29.11.2010).

Del Grosso S.J., Parton W.J., Mosier A.R., Ojima D.S., Potter C.S., Borken W., Brumme R., Butterbach-Bahl K., Crill P.M.,

Dobbie K., Smith K.A. 2000. General $\mathrm{CH}_{4}$ oxidation model and comparisons of $\mathrm{CH}_{4}$ oxidation in natural and managed systems // Global Biogeochemical Cycles. V. 14. No. 4. P. 999-1019.

De Visscher A., Boeckx P., Van Cleemput O. 1998. Interaction between Nitrous Oxide formation and Methane oxidation in Soils

Influence of Cation Exchange Phenomena // Journal of Environmental Quality. V. 27. P. 679-687.

De Visscher A., Schippers M., Van Cleemput O. 2001. Short-term kinetic response of enhanced methane oxidation in landfill cover soils to environmental factors // Biology and Fertility of Soils. V. 33. P. 231-237.

Dunfield P., Knowles R. 1995. Kinetics of Inhibition of Methane Oxidation by Nitrate, Nitrite, and Ammonium in a Humisol // Applied and Environmental Microbiology. V. 61. P. 3129-3135.

Dörr H., Katruff L., Levin I. 1993. Soil texture parameterization of the methane uptake in aerated soils // Chemosphere. V. 26. No. 1-4. P. 697-713.

Dutaur L., Verchot L.V. 2007. A global inventory of the soil $\mathrm{CH}_{4}$ sink // Global Biogeochemical Cycles. V. 21. GB4013.

DOI:10.1029/2006GB002734.

Fan S.M., $\quad$ Wofsy S.C., $\quad$ Bakwin P.S., $\quad$ Jacob D.J., $\quad$ Anderson S.M., $\quad$ Kebabian P.L., $\quad$ McManus J.B., $\quad$ Kolb C.E. 1992. Micrometeorological Measurements of $\mathrm{CH}_{4}$ and $\mathrm{CO}_{2}$ Exchange Between the Atmosphere and Subarctic Tundra // Journal of Geophysical Research. V. 97. No. D15. P. 16627-16643.

Glagolev M., Kleptsova I., Filippov I., Maksyutov S., Machida T. 2011. Regional methane emission from West Siberia mire landscapes // Environmental Research Letters. V. 6. N. 4. 045214. DOI: 10.1088/1748-9326/6/4/045214. Также доступна по URL: http://iopscience.iop.org/1748-9326/6/4/045214/pdf/1748-9326_6_4_045214.pdf

Glagolev M., Uchiyama H., Lebedev V., Utsumi M., Smagin A., Glagoleva O., Erohin V., Olenev P., Nozhevnikova A. 2000. Oxidation and Plant-Mediated Transport of Methane in West Siberian Bog // Proceedings of the Eighth Symposium on the Joint Siberian Permafrost Studies between Japan and Russia in 1999. Tsukuba: Isebu. P. 143-149.

Grant R.F., Roulet N.T. 2002. Methane efflux from boreal wetlands: Theory and testing of the ecosystem model Ecosys with chamber and tower flux measurements // Global Biogeochemical Cycles. V. 16. No. 4. 1054. DOI:10.1029/2001GB001702.

GRASS Development Team. 2011. Geographic Resources Analysis Support System (GRASS) Software. Open Source Geospatial Foundation Project. URL: http://grass.osgeo.org (дата обращения: 19.05.2011).

Kammann C., Grünhage L., Jäger H.-L., Wachinger G. 2001. Methane fluxes from differentially managed grassland study plots: the important role of $\mathrm{CH}_{4}$ oxidation in grassland with a high potential for $\mathrm{CH}_{4}$ production // Environmental Pollution. V. 115. P. $261-273$.

King G.M., Adamsen A.P.S. 1992. Effects of Temperature on Methane Consumption in a Forest Soil and in Pure Cultures of the Methanotroph Methylomonas rubra // Applied and Environmental Microbiology. V. 58. No. 9. P. 2758-2763.

Martens C.S., Albert D.B., Alperin M.J. 1998. Biogeochemical processes controlling methane in gassy coastal sediments - Part 1. A model coupling organic matter flux to gas production, oxidation and transport // Continental Shelf Research. V. 18. P. 1741-1770.

Meirink J.F., Bergamaschi P., Frankenberg C., d'Amelio M.T.S., Dlugokencky E.J., Gatti L.V., Houweling S., Miller J.B., Röckmann T., Villani M.G., Krol M.C. 2008. Four-dimensional variational data assimilation for inverse modeling of atmospheric methane emissions: Analysis of SCIAMACHY observations // Journal of Geophysical Research. V. 113. D17301. DOI:10.1029/2007JD009740.

Mikaloff Fletcher S.E., Tans P.P., Bruhwiler L., Miller J.B., Heimann M. 2004. $\mathrm{CH}_{4}$ sources estimated from atmospheric observations of $\mathrm{CH}_{4}$ and its ${ }^{13} \mathrm{C} /{ }^{12} \mathrm{C}$ isotopic ratios: 1. Inverse modeling of source processes // Global Biogeochemical Cycles. V. 18. GB4004. DOI:10.1029/2004GB002223.

Morishita T., Hatano R., Nagata O., Sakai K., Koide T., Nakahara O. 2004. Effect of Nitrogen Deposition on $\mathrm{CH}_{4} \mathrm{Uptake} \mathrm{in}$ Forest Soils in Hokkaido, Japan // Soil Science and Plant Nutrition. V. 50. No. 8. P. 1187-1194.

Morishita T., Matsuura Y., Zyryanova O.A., Abaimov A.P. 2006. $\mathrm{CO}_{2}, \mathrm{CH}_{4}$, and $\mathrm{N}_{2} \mathrm{O}$ fluxes from a larch forest soil in Central Siberia // Symptom of Environmental Change in Siberian Permafrost Region / Hatano R. and Guggenberger G. (Eds.). Sapporo: Hokkaido University Press. P. 1-9.

NASA Land Processes Distributed Active Archive Center (LP DAAC), USGS/Earth Resources Observation and Science (EROS) Center, Sioux Falls, South Dakota. URL: http://lpdaac.usgs.gov/get_data (дата обращения: 19.05.2011).

Petrescu A.M.R., van Huissteden J.C., Jackowicz-Korczynski M., Yurova A., Christensen T.R., Crill P.M., Bäckstrand K., Maximov T.C. 2008. Modelling $\mathrm{CH}_{4}$ emissions from arctic wetlands: effects of hydrological parameterization // Biogeosciences. V. 5 . P. 111-121. URL (дата обращения 22.12.2010): http://www.biogeosciences.net/5/111/2008/bg-5-111-2008.pdf

Potter C.S., Davidson E.A., Verchot L.V. 1996. Estimation of global biogeochemical controls and seasonality in soil methane consumption // Chemosphere. V. 32. P. 2219-2246.

Ridgwell A.J., Marshall S.J., Gregson K. 1999. Consumption of atmospheric methane by soils: A prosess-based model // Global Biogeochemical Cycles. V. 13. No. 1. P. 59-70.

Sabrekov A.F., Kleptsova I.E., Glagolev M.V., Maksyutov Sh.Sh., Machida T. 2011. Methane emission from middle taiga oligotrophic hollows of Western Siberia // Вестник ТГПУ. Вып. 5. С. 135-143. Также доступна по URL (дата обращения 19.06.2011): http://vestnik.tspu.ru/files/PDF/articles/sabrekov_a._f._135_143_5_107_2011.pdf P. 715-720.

Striegl R.G. 1993. Diffusional limits to the consumption of atmospheric methane by soils // Chemosphere. V. 26. No. 1-4. 
Tang J., Zhuang Q., Shannon R.D., White J.R. 2010. Quantifying wetland methane emissions with process-based models of different complexities // Biogeosciences. V. 7. P. 3817-3837. DOI:10.5194/bg-7-3817-2010. URL (дата обращения 22.12.2010): www.biogeosciences.net/7/3817/2010/

Van Huissteden J., van den Bos R., Alvarez I.M. 2006. Modelling the effect of water-table management on $\mathrm{CO}_{2}$ and $\mathrm{CH}_{4}$ fluxes from peat soils // Netherlands Journal of Geosciences. V. 85. No. 1. P. 3-18.

Visvanathan C., Pokhrel D., Cheimchaisri W., Hettiaratchi J.P.A., Wu J.S. 1999. Methanotrophic activities in tropical landfill cover soils: effects of temperature, moisture content and methane concentration // Waste Management \& Research. V. 17. P. $313-323$.

Walter B.P., Heimann M., Matthews E. 2001. Modeling modern methane emissions from natural wetlands 1. Model description and results // Journal of Geophysical Research. V. 106. No. D24. P. 34189-34206.

Walter B.P., Heimann M., Shannon R.D., White J.R. 1996. A process-based model to derive methane emissions from natural wetlands // Geophysical Research Letters. V. 23. P. 3731-3734.

Wania R. 2007. Modelling northern peatland land surface processes, vegetation dynamics and methane emissions: PhD thesis. Bristol: University of Bristol.

Whiticar M.J. 1999. Carbon and hydrogen isotope systematics of bacterial formation and oxidation of methane // Chemical Geology. V. 161. P. 291-314.

Zelenev V.V. 1996. Assessment of the Average Annual Methane Flux from the Soils of Russia. WP-96-51. Laxenburg, Austria: International Institute for Applied Systems Analysis.

Zhuang Q., Melillo J.M., Kicklighter D.W., Prinn R.G., McGuire A.D., Steudler P.A., Felzer B.S., Hu S. 2004. Methane fluxes between terrestrial ecosystems and the atmosphere at northern high latitudes during the past century: A retrospective analysis with a process-based biogeochemistry model // Global Biogeochemical Cycles. V. 18. GB3010. DOI:10.1029/2004GB002239.

Zobler L. 1986. A world soil file for global climate modeling. NASA TM-87802. National Aeronautics and Space Administration. Washington, D.C. Данные доступны по URL: http://data.giss.nasa.gov/landuse/soilunit.html (дата обращения: 19.05.2011).

\section{ПРИЛОЖЕНИЕ: СТАТИСТИЧЕСКИЙ АНАЛИЗ ЗНАЧИМОСТИ ОТЛИЧИЙ ПОГЛОЩЕНИЯ СН 4 ПОЧВАМИ РАЗНОЙ СТРУКТУРЫ}

Поскольку Dutaur and Verchot [2007] приводят данные о количестве измерений удельного потока поглощения метана, выполненных в разных условиях, то возможно провести статистический анализ значимости отличий поглощения на почвах той или иной структуры. При поверхностном анализе табл. 2 представляется, что удельные потоки различаются в почвах разной структуры (ср. $0.20 \Gamma^{-} \mathrm{m}^{-2} \cdot{ }^{\circ}$ гд $^{-1}$ для «Fine» и $0.42 \Gamma^{*} \mathrm{M}^{-2} \cdot{ }^{-1}$ го $^{-1}$ для «Coarse»).

Но отличие незначительно; при этом возникает подозрение, не вызвано ли это отличие лишь случайными ошибками эксперимента [Румшиский, 1971, с. 35-36]. Для сравнения между собой двух средних, полученных по выборкам из нормально распределенных генеральных совокупностей, применяется критерий Стьюдента. Пусть заданы две случайные выборки с объемами $n_{1}$ и $n_{2}$. Первая выборка взята из нормально распределенной совокупности с параметрами $m_{x}$ и $\sigma_{x}^{2}$ (соответственно среднее и дисперсия), вторая - из совокупности с параметрами $m_{y}$ и $\sigma_{y}{ }^{2}$. По выборкам получены оценки для этих параметров: $x, s_{x}^{2}$ и $y, s_{y}^{2}$. Требуется проверить нулевую гипотезу: $m_{x}=m_{y}$. Если число степеней свободы дисперсий $s_{x}{ }^{2}$ и $s_{y}{ }^{2}$, соответственно, составляют $f_{1}=n_{1}-1$ и $f_{2}=n_{2}-1$, то можно использовать следующий приближенный критерий. Вычисляется величина

$$
T=\left[v_{1} \cdot t_{1-p / 2}\left(f_{1}\right)+v_{2} \cdot t_{1-p / 2}\left(f_{2}\right)\right] /\left(v_{1}+v_{2}\right)^{1 / 2},
$$

где $v_{1}=s_{x}{ }^{2} / n_{1}$ и $v_{2}=s_{y}{ }^{2} / n_{2}$, Нулевая гипотеза отвергается если

$$
|x-y|>T \text {. }
$$

Сформулированный критерий является двусторонним, он превращается в односторонний при замене $p / 2$ на $p$ [Блохин, 2002, с. 54-56]. Как видим, для вычисления $T$ необходимо знать $t_{1-p / 2}(f)$ - квантиль распределения Стьюдента при $f$ степенях свободы. Таблицы этих квантилей часто встречаются в литературе по математической статистике - см., например, [Румшиский, 1971, с. 174], где даны, как раз, квантили двустороннего распределения). Также эти квантили рассчитываются широко распространенными компьютерными интерактивными системами (см. например, функцию tinv в системе MATLAB, использующую одностороннее распределение, или функцию СТЬЮДРАСПОБР в MS Excel, дающую двустороннее).

Результаты расчетов различия средних удельных потоков поглощения метана в почвах с разной структурой приведены в нижеследующей таблице. Как видим, вероятности того, что удельные потоки различаются, малы: они нигде не поднимаются даже до 0.95 (мы упоминаем именно это значение, поскольку общеизвестно, что обычные требования надежности в биологических и почвенных исследованиях соответствуют вероятности 0.95 - см., например, [Бейли, 1970, с. 39; Чернавина с соавт., 
1978, с. 189; Дмитриев, 1995, с. 135]). Таким образом можно считать, что, согласно данным [Dutaur and Verchot, 2007], почвы разной структуры не различаются по интенсивности поглощения $\mathrm{CH}_{4}$.

\begin{tabular}{|c|c|c|c|c|c|}
\hline \multicolumn{2}{|c|}{ Количество измерени } & 85 & 121 & 46 & 54 \\
\hline \multirow{2}{*}{$\begin{array}{l}\underset{\left(2: M^{-2} \cdot 20 \delta^{-1}\right)}{C H_{4}} \\
H_{4}\end{array}$} & среднее & 0.42 & 0.33 & 0.20 & 0.31 \\
\hline & CKO & 1.45 & 1.34 & 0.42 & 0.96 \\
\hline \multicolumn{2}{|c|}{ Структура } & Coarse & Medium & Fine & Organic \\
\hline \multicolumn{2}{|c|}{ Coarse } & 0 & 0.34 & 0.80 & 0.40 \\
\hline \multicolumn{2}{|l|}{ Medium } & 0.34 & 0 & 0.65 & 0.08 \\
\hline \multicolumn{2}{|l|}{ Fine } & 0.80 & 0.65 & 0 & 0.54 \\
\hline \multicolumn{2}{|l|}{ Organic } & 0.40 & 0.08 & 0.54 & 0 \\
\hline
\end{tabular}

Вероятности различия ППП в почвах с разной структурой (по данным [Dutaur and Verchot, 2007, Table 2]).

В заключение приведем текст программы, по которой производились расчеты:

function $\mathrm{G}=\mathrm{COMPARISON}(\mathrm{Mx}, \mathrm{My}, \mathrm{Sx}, \mathrm{Sy}, \mathrm{Nx}, \mathrm{Ny}, \mathrm{P})$;

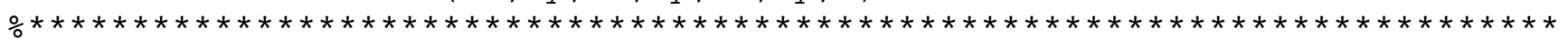

$\circ$

СРАВНЕНИЕ МЕЖДУ СОБОЙ ДВУХ СРЕДНИХ, ПОЛУЧЕННЫХ ПО ВЫБОРКАМ

$\frac{\circ}{0}$

ИЗ НОРМАЛЬНО РАСПРЕДЕЛЕННЫХ ГЕНЕРАЛЬНЫХ СОВОКУПНОСТЕЙ

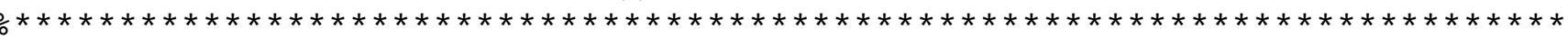

ПРИМЕЧАНИЯ :

1) Сравнение производится при помощи критерия, описанного в [Блохин, * 2002: c. 55-56]. Выходная переменная $\mathrm{G}=\mathrm{abs}(\mathrm{Mx}-\mathrm{My}) / \mathrm{T}$ по терминологии *

Блохина.

2) Критерий является двусторонним. Это не соответствует функции tinv *

\% (из Statistics Toolbox), поэтому используется специальное преобразо- *

о вание вероятности.

o

○ СИНТАКСИС ВЫЗОВА: Т=COMPARISON (Mx, My, Dx, Dy, Nx, Ny, P) ;

П ПРИМЕР ВЫЗОВА: Р=0.34; G=COMPARISON $(0.42,0.33,1.45,1.34,85,121, \mathrm{P})$

ㅁ Для этого примера будет получен следующий результат:

$\div \mathrm{G}=1.0252$

\% т.е. если по одной выборке, содержащей 85 элементов, получено среднее *

о 0.42 и среднее квадратическое отклонение (СКО) 1.45, а по другой выбор- *

\% ке, содержащей 121 элемент, получено среднее 0.33 и СКО 1.34, то веро- *

о ятность того, что средние этих двух выборок не отличаются составляет *

\% примерно 0.34 .

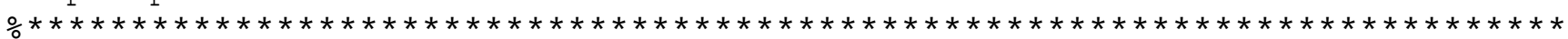

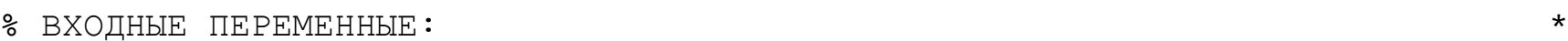

익 Му - средние, полученные, соответственно, по 1-ой и 2-ой выборкам; *

\% Sx, Sy - соответствующие средние квадратические отклонения (Sx, Sy > 0); *

\% Nx, Ny - объемы, соответственно, 1-ой и 2-ой выборок (Nx, Ny > 1); * *

○ $\mathrm{P}$ - проверяемая вероятность $(0<\mathrm{P}<1)$ нулевой гипотезы (о том, что Мх=Му) *

응

○ ВЫХОДНАЯ ПЕРЕМЕННАЯ :

G - значение китерия (если G>1, то нулевая гипотеза отвергается). * o

о ДАТА: 02.08 .2012 ЯЗЫК: MATLAB 7.0 ПРОГРАММИСТ: Глаголев М.В. *

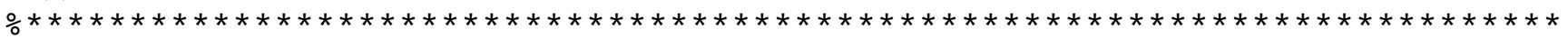

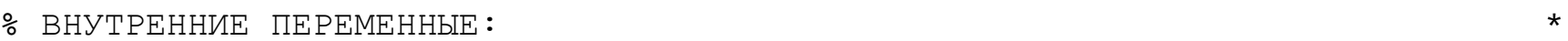

\% fl, f2 - число степеней свободы дисперсий Dx и Dy, соответственно; *

\% Т - См. [Блохин, 2002: с. 55];

\% v1, v2 - вспомогательные переменные;

응

НЕОБХОДИМЫЕ ВНЕШНИЕ ФУНКЦИИ (из Statistics Toolbox):

$\therefore$ tinv - Inverse of Student's T cumulative distribution function.

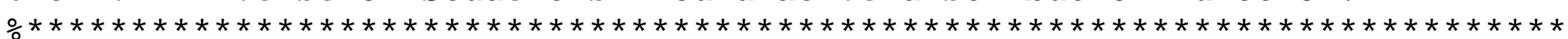

о ЛИТЕРАТУРА: Блохин А.В. 2002. Теория эксперимента. Минск: БГУ. Ч. 1.

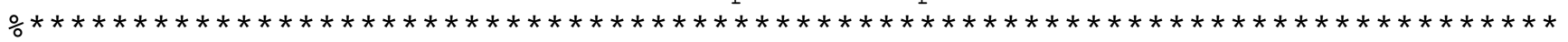




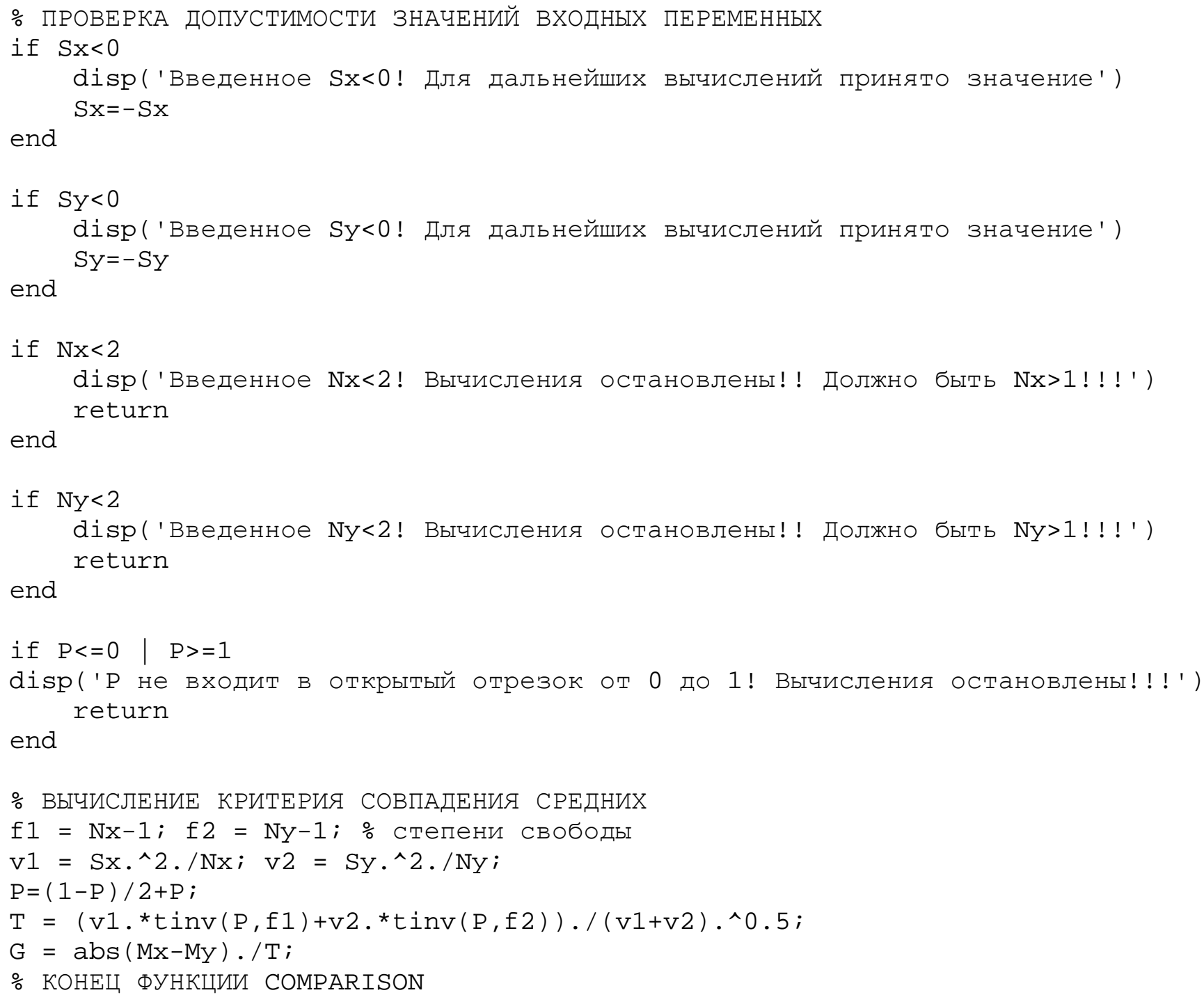

\title{
INVENTORY OF SOIL METHANE CONSUMPTION
}

\author{
Glagolev M.V., Filippov I.V.
}

On the basis of the various rates measured for a wide variety of soils, global soil methane oxidation ranges between 5 and 60 Tg/year. These values are approximately 1 to $10 \%$ of the current estimates for net methane flux to the atmosphere [Dörr et al., 1993].

Methane uptake by soils is an appropriate process to model globally because the probable controls are simple relative to many other microbially mediated soil processes of trace gas production and consumption [Potter et al., 1996]. Potential microbial decomposition rate, vegetation cover, soil temperature, organic matter content, pH [Born et al., 1990; Dörr et al., 1993] as well as latitude, annual mean rainfall, and annual mean temperature [Dutaur and Verchot, 2007] are found to be of minor influence on the methane flux from the atmosphere into the soil.

Principal methods of gas flux upscaling such as simplest inventory, using of mathematical models and inverse modelling are described in this study by an example of methane uptake by soils. Different implementations of simplest inventory approach as $\mathrm{CH}_{4}$ uptake estimation in soils of various bioms and/or structure are considered.

Methane consumption in aerated soils is mainly controlled by the gas transport resistance within the soil as it was found by Born et al. [1990] and Dörr et al. [1993]. However this assertion is seemed to be correct only for similar bioms or at local areas. The inventory of Dutaur and Verchot [2007] showed that ecosystem type, geographic zone, and soil texture strongly control $\mathrm{CH}_{4}$ uptake. The ecosystem type accounted for the largest part of the variation in the global data set while established uptake estimation approach based on our knowledges about soil structure is proved to be statistically unreliable at significance level 0.05 (usually used in biometric and pedometric studies).

At the final section simplest inventory approach applied to the methane uptake by Russian soils is discussed. It was shown that consumption estimations obtained for Russian soils vary considerably according to the different studies. This heterogeneity indicates significant gaps in our knowledge of methane emission and consumption in Russian soils and 
necessity of the future research. Probable methane uptake by Russian soils similar to other estimations can be accepted as 3.6 Mt $y$ r.

The authors acknowledge the financial support by the European Union FP7-ENVIRONMENT project PAGE21 under contract no. GA282700.

Key words: methane, Russian soils, methane consumption by soils.

Поступила в редакцию: 07.07.2011 Переработанный вариант: 24.10.2011 